\title{
Resolvin D1 Programs Inflammation Resolution by Increasing TGF- $\beta$ Expression Induced by Dying Cell Clearance in Experimental Autoimmune Neuritis
}

\author{
Bangwei Luo, ${ }^{1}$ Fuyu Han, ${ }^{1}$ Kai Xu, ${ }^{1}$ Jinsong Wang, ${ }^{1}$ Zongwei Liu, ${ }^{1}$ Zigang Shen, ${ }^{1}$ Jia Li, ${ }^{1}$ Yu Liu, ${ }^{1}$ Man Jiang, ${ }^{1}$ \\ Zhi-Yuan Zhang, ${ }^{2,3}$ and 10 Zhiren Zhang ${ }^{1}$ \\ ${ }^{1}$ Institute of Immunology of PLA, Third Military Medical University, Chongqing 400038, China, ${ }^{2}$ Department of Pathology, Nanjing Medical University, \\ Nanjing 210029, China, and ${ }^{3}$ Division of Immunopathology of the Nervous System, Institute of Pathology and Neuropathology, University of Tuebingen, \\ D-72076 Tuebingen, Germany
}

\begin{abstract}
Experimental autoimmune neuritis (EAN) is the animal model of human acute inflammatory demyelinating polyradiculoneuropathies (AIDP), an auto-immune inflammatory demyelination disease of the peripheral nervous system (PNS) and the world's leading cause of acute autoimmune neuromuscular paralysis. EAN and AIDP are characterized by self-limitation with spontaneous recovery; however, endogenous pathways that regulate inflammation resolution in EAN and AIDP remain elusive. A pathway of endogenous mediators, especially resolvins and clearance of apoptotic cells, may be involved. Here, we determined that resolvin D1 (RvD1), its synthetic enzyme, and its receptor were greatly increased in PNS during the recovery stage of EAN. Both endogenous and exogenous RvD1 increased regulatory T (Treg) cell and anti-inflammatory macrophage counts in PNS, enhanced inflammation resolution, and promoted disease recovery in EAN rats. Moreover, RvD1 upregulated the transforming growth factor- $\beta$ (TGF- $\beta$ ) level and pharmacologic inhibition of TGF- $\beta$ signaling suppressed RvD1-induced Treg cell counts, but not anti-inflammatory macrophage counts, and RvD1-improved inflammation resolution and disease recovery in EAN rats. Mechanistically, the RvD1-enhanced macrophage phagocytosis of apoptotic T cells leading to reduced apoptotic T-cell accumulation in PNS induced TGF- $\beta$ production and caused Treg cells to promote inflammation resolution and disease recovery in EAN. Therefore, these data highlight the crucial role of RvD1 as an important pro-resolving molecule in EAN and suggest its potential as a therapeutic target in human neuropathies.
\end{abstract}

Key words: apoptotic cell clearance; experimental autoimmune neuritis; inflammation resolution; macrophages; regulatory T cells; resolvin D1

\section{Significance Statement}

Experimental autoimmune neuritis (EAN) is the animal model of human acute inflammatory demyelinating polyradiculoneuropathies, an auto-immune inflammatory demyelination disease of the peripheral nervous system (PNS) and the world's leading cause of acute autoimmune neuromuscular paralysis. Here, we demonstrated that resolvin D1 (RvD1) promoted macrophage phagocytosis of apoptotic T cells in PNS, thereby upregulating transforming growth factor- $\beta$ by macrophages, increased local Treg cell counts, and finally promoted inflammation resolution and disease recovery in EAN. These data highlight the crucial role of RvD1 as an important pro-resolving molecule in EAN and suggest that it has potential as a therapeutic target in human neuritis.

\section{Introduction}

Human acute inflammatory demyelinating polyradiculoneuropathy (AIDP) is the most common subtype of Guillain-Barré

Received Jan. 3, 2016; revised July 20, 2016; accepted July 26, 2016.

Author contributions: Z.Z. designed research; B.L., F.H., K.X., J.W., Z.L., Z.S., J.L., Y.L., M.J., and Z.-Y.Z. performed research; B.L., F.H., K.X., J.W., Z.L., Z.S., J.L., Y.L., M.J., Z.-Y.Z., and Z.Z. analyzed data; Z.-Y.Z. and Z.Z. wrote the paper.

This work was supported by the National Natural Science Foundation of China (Grant 81471570 to Z.Z.) and The National Key Research and Development Program of China (Grant 2016YFA0502204 to Z.Z.). We thank X. Fu for technical support for flow cytometry and H.J. Schluesener for discussion of the manuscript. syndrome, the world's leading cause of acute autoimmune neuromuscular paralysis, and is caused by an autoimmune attack on the peripheral nervous system (PNS) (Hughes and Cornblath,

The authors declare no competing financial interests.

Correspondence should be addressed to either of the following: Zhi-Yuan Zhang, Department of Pathology, Nanjing Medical University, Hanzhong Road 140, Nanjing 210029, China, E-mail: zhiyuan.zhang@medizin.uni-tuebingen.de or zzy@njmu.edu.cn; or Zhiren Zhang, Institute of Immunology of PLA, Third Military Medical University, 30 Gaotanyan Main Street, Chongqing 400038, China. E-mail: zhangzhiren@yahoo.com.

DOI:10.1523/JNEUROSC1.0020-16.2016

Copyright $\odot 2016$ the authors $\quad 0270-6474 / 16 / 369590-14 \$ 15.00 / 0$ 
2005; Soliven, 2012). AIDP is characterized by self-limitation with spontaneous recovery, which strongly indicates the existence of a regulatory network capable of resolving vigorous autoimmune inflammation. Unraveling the mechanisms underlying the self-limitation of autoimmune neuropathy may not only deepen our understanding of this disorder, but may also help with the development of new therapeutics. Experimental autoimmune neuritis (EAN) is a widely applied animal model used to investigate the mechanism and therapeutic principles of AIDP (Hughes and Cornblath, 2005; Soliven, 2012).

As a helper T (Th)-cell-mediated autoimmune disorder, the apoptosis of auto-aggressive $\mathrm{T}$ cells is a well established mechanism for terminating the autoimmune inflammatory responses in EAN (Zettl et al., 1994; Weishaupt et al., 2001). However, an efficient clearance of apoptotic cells is necessary to prevent the leakage of harmful substances from dying cells due to so-called "secondary necrosis," which can cause further damage to local tissues (Yun et al., 2008). Moreover, the clearance of apoptotic cells by local macrophages can lead to a switch of activated macrophages into an anti-inflammatory functional phenotype (Fadok et al., 1998; Huynh et al., 2002), which may further induce Th cell differentiation toward the regulatory phenotype (Treg) via the established anti-inflammatory cytokine milieu (Annunziato et al., 2008). Interestingly, we and others have found that the induction of Treg cells and anti-inflammatory macrophages is crucial for inflammation resolution and the spontaneous recovery of neuropathies and EAN (Zhang et al., 2009a; Zhang et al., 2010; Meyer zu Hörste et al., 2014; Luchting et al., 2015). Therefore, the phagocytosis of apoptotic T cells seems to be a key event that leads to autoimmune inflammation resolution and connects the known pro-resolving factors in EAN. However, the pathways regulating apoptotic cell clearance and the subsequent inflammation resolution in EAN remain unknown.

Resolvins are a new paradigm of endogenous mediators that promote the resolution of inflammation and stimulate the return to homeostasis (Tabas and Glass, 2013). Resolvin D1 (RvD1) is an important member of resolvins and is biosynthesized from $\omega$-3 docosahexaenoic acid (DHA) via 15-lipoxygenase (15-LOX) and 5-LOX interactions (Levy, 2010) in humans, but via 12/15LOX and 5-LOX interactions in rodents (Titos et al., 2011). Two receptors, the LXA4 receptor (ALX/FPR2) and the orphan G-protein-coupled receptor 32 (GPR32), have been shown to transmit RvD1 signals (Krishnamoorthy et al., 2010), but only ALX/FPR2 has been identified in rodents (Recchiuti, 2013). RvD1 is mainly detected as being expressed on neutrophils and macrophages (Sun et al., 2007). RvD1 can regulate the migration of neutrophils and enhances the macrophage phagocytosis of apoptotic leukocytes in an ALX/FPR2-dependent manner, which contributes to the resolution of inflammation (Hong et al., 2003; Sun et al., 2007; Spite et al., 2009; Krishnamoorthy et al., 2010). Although RvD1 is known to promote acute inflammation resolution, its contribution to the resolution of autoimmune inflammation in autoimmune diseases, including EAN, remains to be explored.

\section{Materials and Methods}

EAN induction, treatment, and clinical score evaluation. EAN was induced in male Lewis rats (8-10 weeks of age; Vital River) and all animal procedures and protocols were approved by the local Administration District Official Committee. EAN was induced and EAN rats were clinically monitored daily for body weight and neurological signs of EAN in a blinded manner, as described previously (Zhang et al., 2009a).

For treatment, EAN rats received intraperitoneal (i.p.) injection of RvD1 (Cayman Chemical, $5 \mu \mathrm{g} / \mathrm{kg} / \mathrm{d}$, i.p.) or Boc-1 (a specific antagonist
Table 1. Antibodies used in this study

\begin{tabular}{ll}
\hline Anti-CD3 antibody & Tlymphocytes \\
Anti-CD4 antibody & CD4 + Th cells \\
Anti-CD68 antibody & Macrophages \\
Anti-CD16/32 antibody & Fc $\gamma$ ll \\
Anti-Foxp3 antibody & Treg cells \\
Anti-TGF- $\beta$ antibody & TGF- $\beta$ expression \\
Anti-annexin-V antibody & Apoptosis \\
Anti-ED1 antibody & Macrophages \\
Anti-ED2 antibody & Anti-inflammatory macrophages \\
Anti-W3/13 antibody & Tlymphocytes \\
Anti-OX22 antibody & B cells \\
Anti-FPR2 antibody & ALX receptor expression \\
\hline
\end{tabular}

of ALX; Chinapeptide, $5 \mathrm{mg} / \mathrm{kg} / \mathrm{d}$, i.p.) daily from day 10 to day 22. In some cases, $\mathrm{RvD1}$ was given together with SD-208 (a TGF- $\beta$ receptor antagonist; Santa Cruz Biotechnology, $20 \mathrm{mg} / \mathrm{kg} / \mathrm{d}$, i.p.) or SD-208 alone was given. The RvD1, Boc-1, and SD-208 were dissolved in $0.9 \%$ endotoxinfree saline and the same volume of saline was given to control groups.

Histological analysis. Immunohistochemical staining, including single labeling and double labeling and the following micro-image analysis, were performed as described previously (Zhang et al., 2010; Zhang et al., 2011). The following antibodies were used in this study: ED1 antibody for macrophages (1:100; Serotec), W3/13 antibody for T lymphocytes (1:50; Serotec), OX22 antibody for B cells (1:200; Serotec), ED2 antibody for anti-inflammatory macrophages (1:100; Serotec), or FPR2 antibody for ALX receptor (1:50; Alomone). All antibodies used in this study are summarized in Table 1.

For some sciatic nerves, electron microscopy was also performed as described previously (Pilartz et al., 2002). Axonal demyelination is defined as normal axons with their myelin sheaths disappeared or breaking down. The total number of normally myelinated and fully demyelinated axons was manually counted by an investigator blinded toward previous treatment using the CellCounter plugin of ImageJ. The percentage of intact and demyelinated axons was calculated and compared between groups (Mausberg et al., 2011).

Tissue preparation, RNA isolation, reverse transcription, and real-time $P C R$. After treatments, sciatic nerves, inguinal lymph nodes, and spleens were quickly removed and total RNA was isolated and reverse transcribed into cDNA, which was used to measure the relative expression of genes using real-time PCR, as described previously (Zhang et al., 2009a). Primers used to measure gene expression are listed in Table 2.

Flow cytometric analysis of Foxp $3^{+}$regulatory $T$ cells and TGF$\beta^{+} C D 68^{+}$cells. For the preparation of mononuclear cells (MNCs) from lymph nodes or spleens, tissues were dissected and passed through a 40 $\mathrm{mm}$ cell strainer, followed by Red Blood Cell Lysis Buffer (BioLegend). For the MNCs from sciatic nerves, tissues were carefully removed and then transferred to RPMI-1640 (Invitrogen) containing 27\% Percoll (GE Healthcare), homogenized, and passed through a steel mesh cell strainer. Subsequently, the cell suspension in 27\% Percoll in RPMI 1640 medium was centrifuged at $1000 \times g$ for $30 \mathrm{~min}$ at $4^{\circ} \mathrm{C}$. The pellet was recovered and washed by RPMI 1640 medium containing $2 \%$ FCS

Treg cells were identified as Foxp $3^{+} / \mathrm{CD}^{+}$cells. MNCs were permeabilized and stained according to the manufacturer's protocol (eBioscience). For determination of CD $68^{+}$TGF- $\beta^{+}$cells, MNCs were incubated for $6 \mathrm{~h}$ in the presence of $50 \mathrm{ng} / \mathrm{ml}$ phorbol-12-myristate-13-acetate (Sigma-Aldrich), $1 \mathrm{mg} / \mathrm{ml}$ ionomycin (Sigma-Aldrich), and $1 \mu \mathrm{g} / \mathrm{ml}$ Brefeldin A (Sigma-Aldrich) in flat-bottomed 96-well plates in RPMI 1640 medium containing $10 \%$ fetal calf serum at a density of $10^{6}$ cells $/ \mathrm{ml}$ at $37^{\circ} \mathrm{C}$ and $5 \% \mathrm{CO}_{2}$. Thereafter, cells were fixed, permeabilized, and incubated with FITC-CD68 antibody (eBioscience) and TGF- $\beta$ antibody (Abcam) according to the standard protocol. For all staining, isotype controls were used. After staining, cells were washed and suspended in PBS and then analyzed with a FASCcanto II (BD Biosciences).

$R v D 1$ and TGF- $\beta$ measurement. After treatment, EAN rats were killed and sciatic nerves, inguinal lymph nodes, and spleens were quickly removed and homogenized in ice-cold RIPA buffer with $1 \mathrm{mg} / \mathrm{ml}$ of a protease inhibitor mixture (Beyotime Institute of Biotechnology, 
Table 2. Primers used in this study

\begin{tabular}{|c|c|}
\hline \multirow[t]{2}{*}{ 12/15-LOX } & Sense TTC AGT GTA GAC GTG GAG \\
\hline & Antisense ATG TAT GCC GGT GCT GGC TAT ATT TAG \\
\hline \multirow[t]{2}{*}{ FPR2 } & Sense ATG GAA GCC AAC TAT TCC ATC \\
\hline & Antisense TCA TAT TGC TTT TAT ATC AAT GTT \\
\hline \multirow[t]{2}{*}{ IL-1 $\beta$} & Sense TGC TGA TGT ACC AGT TGG GG \\
\hline & Antisense CTC CAT GAG CTT TGT ACA AG \\
\hline \multirow[t]{2}{*}{ IFN- $\gamma$} & Sense AAA GACAAC CAG GCC ATC AG \\
\hline & Antisense CTT TTC CGC TTC CTT AGG CT \\
\hline \multirow[t]{2}{*}{ IL-17 } & Sense TGG ACT CTG AGC CGC ATT GA \\
\hline & Antisense GAC GCA TGG CGG ACA ATA GA \\
\hline \multirow[t]{2}{*}{ TGF- $\beta$} & Sense TGA ACC AAG GAG ACG GAA TACAGG \\
\hline & Antisense TAC TGT GTG TCC AGG CTC CAA ATG \\
\hline \multirow[t]{2}{*}{ IL-12p35 } & Sense TGA AGA CCA CGG ACG ACA \\
\hline & Antisense TGT GAT TCA GAG ACC GCA TTA G \\
\hline \multirow[t]{2}{*}{ T-bet } & Sense AAC CAG TAT CCT GTT CCC AGC \\
\hline & Antisense TGT CGC CAC TGG AAG GAT AG \\
\hline \multirow[t]{2}{*}{ Foxp3 } & Sense GCA CAA GTG CTT TGT GCG AGT \\
\hline & Antisense TGT CTG TGG TTG CAG ACG TTG T \\
\hline \multirow[t]{2}{*}{ ROR $\gamma \mathrm{t}$} & Sense CGC ACC AAC CTC TTC TCA CG \\
\hline & Antisense GAC TTC CAT TGC TCC TGC TTTC \\
\hline \multirow[t]{2}{*}{ GATA-3 } & Sense CTC TCC TTT GCT CAC CTT TTC \\
\hline & Antisense AAG AGA TGC GGA (T GGA GTG) \\
\hline \multirow[t]{2}{*}{ Arginase-1 } & Sense AAA GCC CAT AGA GAT TAT CGG AGC G \\
\hline & Antisense AGA CAA GGT CAA CGG CAC TGCC \\
\hline \multirow[t]{2}{*}{$\beta$-actin } & Sense CCG TCT TCC CCT CCA TCG T \\
\hline & Antisense ATC GTC CCA GTT GGT TAC AAT GC \\
\hline
\end{tabular}

Haimen, China). The homogenates were centrifuged at 13,500 rpm for 5 min at $4^{\circ} \mathrm{C}$ and the supernatants were collected for bicinchoninic acid assays (for the detection and quantitation of total protein). RvD1 levels were measured by Resolvin D1 EIA Kit (Cayman Chemical) and TGF- $\beta$ levels were detected by TGF- $\beta$ ELISA kit (R\&D Systems) according to the manufacturer's protocols.

Peritoneal macrophage culture and in vitro apoptotic cell phagocytosis assay. Peritoneal macrophages were isolated from 10- to 12 week-old Lewis rats as described previously (Zhang et al., 2009a). The resulting adherent macrophage monolayer was $>90 \%$ pure according to morphological criteria using Wright-Giemsa staining.

To generate apoptotic cells, Jurkat cells were cultured in RPMI without FCS, and apoptosis was induced with $0.5 \mu \mathrm{g} / \mathrm{ml}$ staurosporine (SigmaAldrich) for $3 \mathrm{~h}$. Staurosporine treatment yielded a population with $90 \%$ apoptotic cells, as measured with FITC-AnnexinV/propidium iodide staining (Sungene Biotech). Apoptotic cells were labeled with pHrodo Green (Invitrogen), a pH-sensitive, phagocytosis-dependent indicator that requires no washing steps or quenchers, according to the manufacturer's instructions.

For phagocytosis assay, peritoneal macrophages were plated in 6-well plates in DMEM with 10\% FCS overnight. pHrodo-labeled apoptotic cells were added to peritoneal macrophages at a ratio of 5:1 (apoptosis cells: macrophages) and cultured at $4^{\circ} \mathrm{C}$ (negative control) or $37^{\circ} \mathrm{C}$ for 60 min. In some cases, macrophages were pretreated with RvD1 with or without $2 \mu \mathrm{M}$ cytochalasin $\mathrm{D}$ (for inhibition of the macrophage phagocytosis, CytD; Sigma-Aldrich) for the indicated times before coincubation with pHrodo-labeled apoptotic cells. After incubation, cells were washed, resuspended, and stained with fluorescence-labeled anti-CD68 (eBioscience). Later, the cells were analyzed by flow cytometry and the proportion of macrophages containing ingested apoptotic cells was determined.

Assay of apoptotic T-cell phagocytosis by macrophages in vivo.

For determining macrophage phagocytosis of apoptotic T lymphocytes in sciatic nerves, collected MNCs were first blocked with antimouse CD16/32 blocking antibody (Sungene Biotech) for $5 \mathrm{~min}$ for blocking nonspecific binding of Ig to Fc receptors, labeled with antimouse CD68 antibody (eBioscience) for $20 \mathrm{~min}$, and then permeabilized with $0.1 \%$ Triton X-100. Subsequently, permeabilized cells were stained with anti-rat $\mathrm{CD} 3$ (eBioscience). The percentage of $\mathrm{CD}^{+} 8^{+} \mathrm{CD}^{+}$cell to $\mathrm{CD}^{+} 8^{+}$cells was determined by flow cytometry.
Tissue apoptotic cell accumulation assay. To measure the accumulation of apoptotic T cells in tissue, MNCs from sciatic nerves of EAN rats were prepared as described above. After being blocked with anti-mouse D16/ 32-blocking antibody for $5 \mathrm{~min}$, MNCs were labeled with anti-rat CD3 antibody and annexin-V (Sungene Biotech) for $20 \mathrm{~min}$ at room temperature. The percentage of $\mathrm{CD}^{+}$Annexin- $\mathrm{V}^{+}$cell to $\mathrm{CD}^{+}$cells was determined by flow cytometry. In addition, the in situ accumulation of apoptotic cells in sciatic nerves of EAN rats was further detected by TUNEL staining (Sungene Biotech) according to the manufacturer's instructions.

T-cell apoptosis assay. Jurkat T cells or MNCs from spleens of Lewis rats were induced with $50 \mathrm{ng} / \mathrm{ml}$ PMA (Sigma-Aldrich) for apoptosis. RvD1 $(250 \mathrm{nM})$ or saline (control) were added for indicated intervals. For Jurkat $\mathrm{T}$ cells, cells were collected and labeled with anti-Annexin V for 20 min at room temperature. For spleen T cells, spleen MNCs were collected and labeled with anti-rat CD3 antibody antibody and anti-Annexin- $\mathrm{V}$ for 20 min at room temperature. Thereafter, the percentages of Annexin- $\mathrm{V}^{+}$ Jurkat $\mathrm{T}$ cells to total cells and $\mathrm{CD} 3^{+}$Annexin- $\mathrm{V}^{+}$spleen $\mathrm{T}$ cells to $\mathrm{CD} 3^{+}$ spleen $\mathrm{T}$ cells were determined by flow cytometry.

Data evaluation and statistical analysis. The unpaired $t$ test or MannWhitney $U$ test was performed to compare differences between treated and control EAN rats using GraphPad Prism version 5.0 software for Windows. For all statistical analyses, significance levels were set at $p<$ 0.05 .

\section{Results}

Temporal expression of RvD1-related molecules in EAN rats

To explore the potential involvement of resolvins, we first investigated the temporal levels of RvD1, its synthetic enzyme 12/15LOX, and its receptor ALX in EAN rats. We induced EAN in Lewis rats by active immunization with autoantigens. Neurological signs of EAN rats appeared around day 7, were maximal at day 15 , declined slowly and became almost undetectable around day 23 after immunization (Fig. 1A). Therefore, we chose four time points for our observation: day 5 (shortly before the disease onset), day 10 (early disease stage), day 15 (disease peak), and day 22 (recovery stage of the disease).

In sciatic nerves, where the initiation and resolution of autoimmune inflammatory reaction occur, a continual increase in levels of RvD1, 12/15-LOX, and ALX was observed, suggesting a potential protective role of the RvD1 cascade in the peripheral nerves of EAN rats (Fig. $1 B$ ). Moreover, we investigated the protein levels of ALX, also known as FPR2, in the sciatic nerves of EAN rats by immunohistochemistry. Similar to its mRNA level change, the accumulation of $\mathrm{ALX}^{+}$cells was observable beginning on day 10, increased thereafter, and peaked at day 22 (Fig. $1 C$ ). Furthermore, we examined the potential target cells of RvD1 by double immunostaining and found that ALX was mainly expressed in $\mathrm{CD}^{+} 8^{+}$macrophages, but not in $\mathrm{W} 3 / 13^{+} \mathrm{T}$ cells or $\mathrm{OX}_{2} 2^{+} \mathrm{B}$ cells, in the sciatic nerves of EAN rats. This finding indicated that RvD1 mainly functions via macrophages in the peripheral nerves of EAN rats (Fig. 1D).

In addition, we monitored the temporal levels of RvD1related molecules in the EAN draining (inguinal) lymph nodes, where the autoimmune response occurs. Interestingly, in contrast to those observed in sciatic nerves, a continual decrease in levels of RvD1, 12/15-LOX and ALX was observed, suggesting that RvD1 may contribute to the maintenance of immunity homeostasis, but is likely not involved in terminating the immune response, in EAN draining lymph nodes (Fig. 1E). Therefore, these results suggest a correlation between the RvD1 cascade and inflammation resolution in the peripheral nerves of EAN. 
A

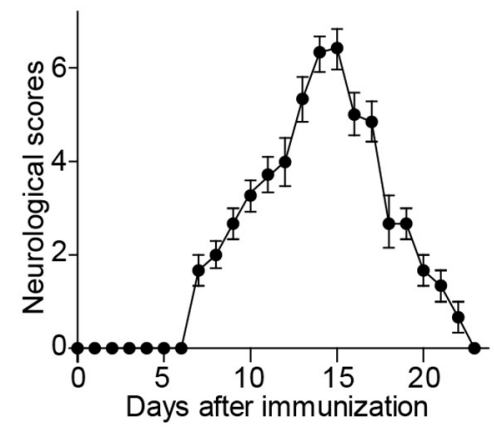

C
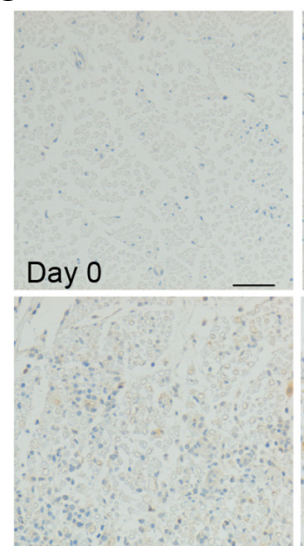

Day 10

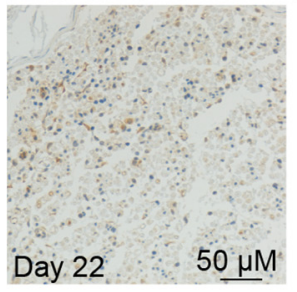

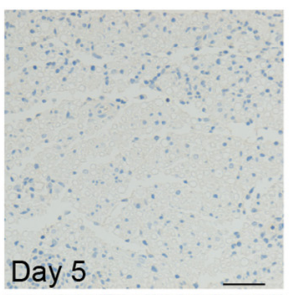

Day 5
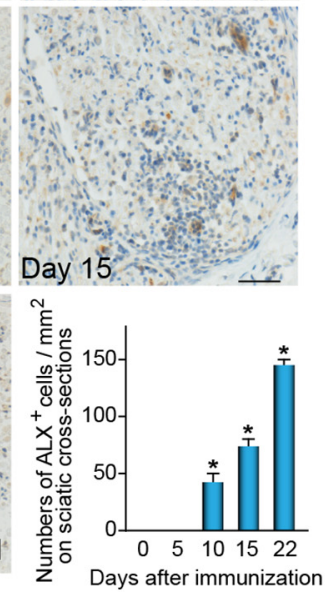

B

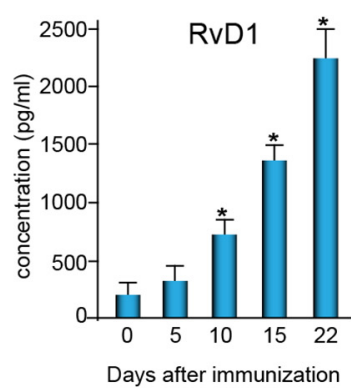

D

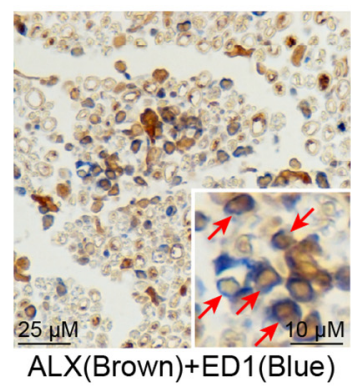

E
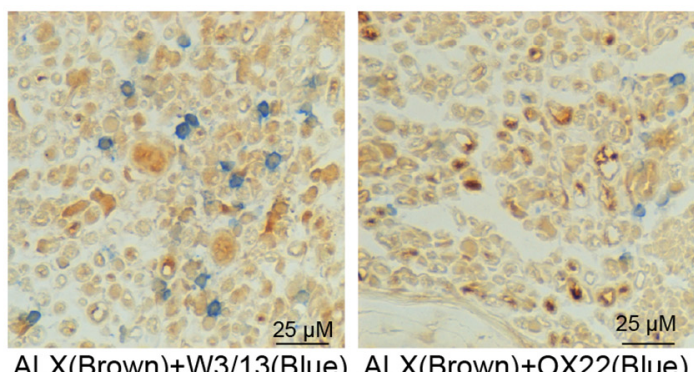

$A L X($ Brown)+W3/13(Blue) $A L X($ Brown $)+O X 22(\overline{B l u e})$
Sciatic nerve
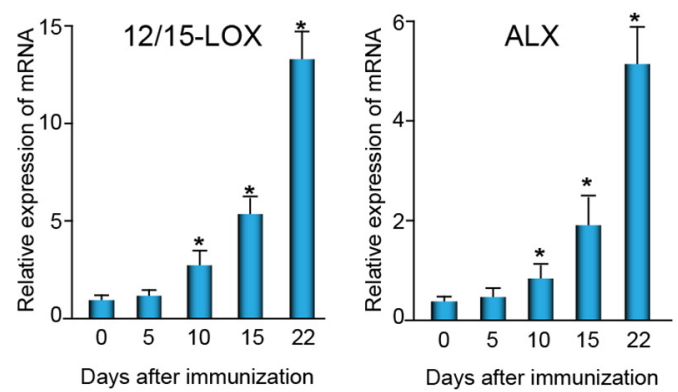

Days after immunization
Inguinal lymph node

RvD1

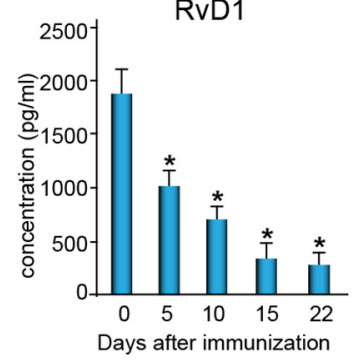

ALX(Brown)+ED1(BIue)

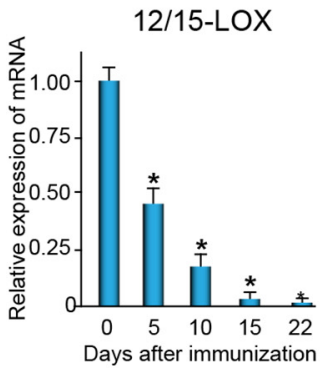

ALX

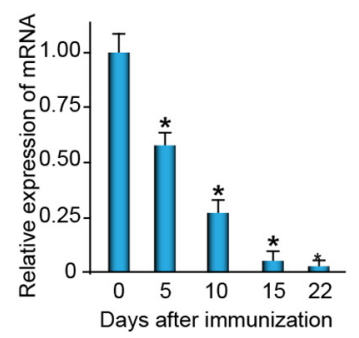

Figure 1. The temporal expression of resolvin D1 (RvD1), its synthetic enzyme, and its receptor in Experimental autoimmune neuritis (EAN) rats. $A$, EAN was induced in Lewis rats by active immunization with autoantigens and the rats were monitored daily for neurological signs of EAN $(n=6)$. $B$, ELISA of RvD1 and real-time PCR (RT-PCR) analysis of 12/15-LOX and ALX in the sciatic nerves of naive and EAN rats $(n=6)$. C, Representative immunostaining and semiquantification of ALX in the sciatic nerves of naive and EAN rats $(n=6)$. $D$, Double immunostaining of ALX in the sciatic nerves of EAN rats. ALX was mainly expressed in CD68 ${ }^{+}$macrophages, but not in W3/13 ${ }^{+} \mathrm{T}$ cells or $0 X 22^{+} B$ cells. $E$, ELISA of RvD1 and RT-PCR analysis of 12/15-LOX and ALX in the draining (inguinal) lymph nodes of naive and EAN rats. Representative data from at least two independent experiments are shown. Error bars indicate standard error of the mean (SEM). ${ }^{*} p<0.05$.

\section{RvD1 promotes EAN recovery}

To identify the endogenous contribution of RvD1 in EAN, we used Boc-1 to inhibit the activity of RvD1 in EAN rats. Boc-1 was administered from day 10 to day 22 . Boc- 1 administration significantly increased the neurological severity and markedly prolonged the duration of disease in EAN rats (Fig. 2A), implicating a delayed inflammation resolution. Furthermore, weight loss was much more pronounced in Boc-1-treated EAN rats than in the control group, indicating a more severe disease course (Fig. 2A). We further investigated axon demyelination/remyelination and degeneration/regeneration in the sciatic nerves of EAN rats after Boc- 1 treatment by electron microscopy from day 15 and day 22 and found that Boc- 1 administration aggravated PNS damage in EAN rats by both disease peak and recovery (Fig. 2B). On day 15, significantly more demyelinated axons indicated deteriorated demyelination by Boc-1 compared with the control group. On day 22 , even bigger differences between control and Boc-1 groups suggested additional impairing effect of Boc-1 during recovery. These data indicate that Boc-1 treatment not only deteriorated demyelination but also impaired recovery.
EAN is characterized by the infiltration of different inflammatory cells into the PNS, which regulates the initiation and resolution of local inflammation. Therefore, we further analyzed the effects of Boc-1 on local inflammatory cell accumulation in the sciatic nerves of EAN rats. Generally, infiltrated autoreactive T cells and B cells are of importance for the initiation and progression of EAN (Soliven, 2012); however, accumulated macrophages in the PNS have a conflicting role in autoimmune neuropathy because they are detrimental in attacking nervous tissue at early stages, but also beneficial in the termination of the inflammatory process and the promotion of recovery in the remission phase of EAN (Zhang et al., 2009a; Brunn et al., 2014). The blocking of RvD1 activity by Boc- 1 markedly increased the accumulation of $\mathrm{T}\left(\mathrm{W} 3 / 13^{+}\right)$and $\mathrm{B}\left(\mathrm{OX} 22^{+}\right)$lymphocytes at day 15 and day 22 in the sciatic nerves of EAN rats, indicating a deteriorated inflammation (Fig. 2C). Interestingly, Boc-1 administration significantly increased the accumulation of macrophages $\left(\mathrm{ED}^{+}\right)$at day 15, but reduced this effect at day 22 in the sciatic nerves of EAN rats, supporting a delayed inflammation resolution (Fig. 2C). Correspondingly, Boc-1 treatment also sig- 
A
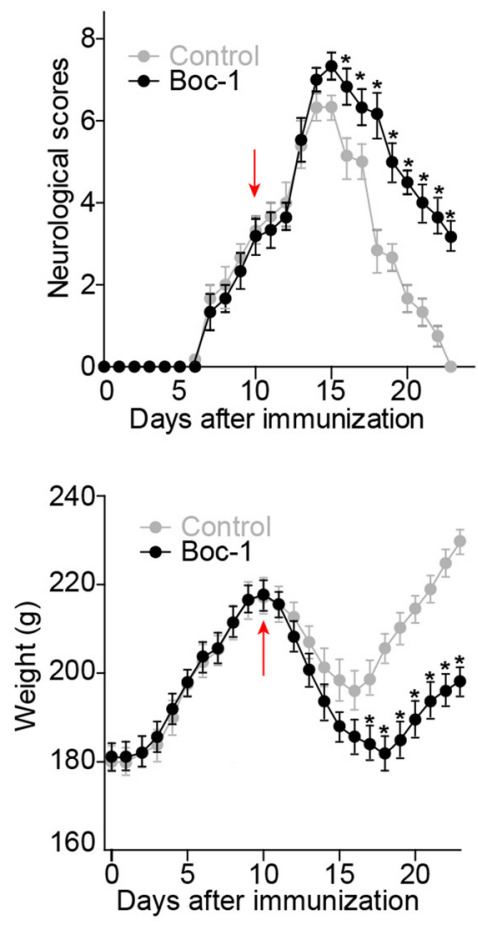

B

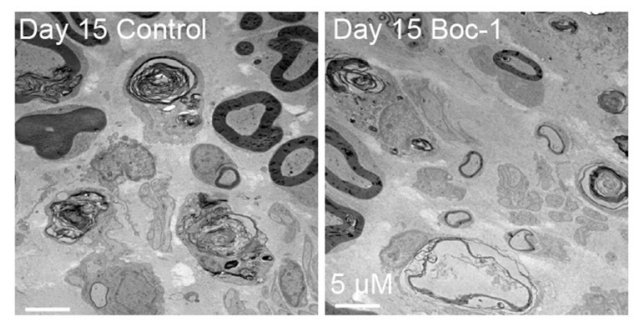

C
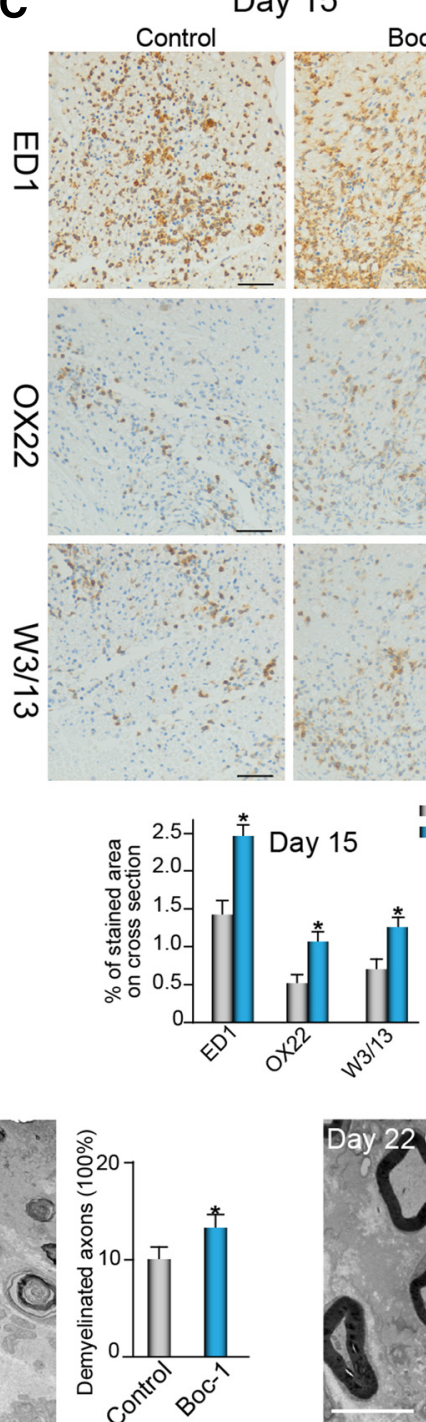

Day 15
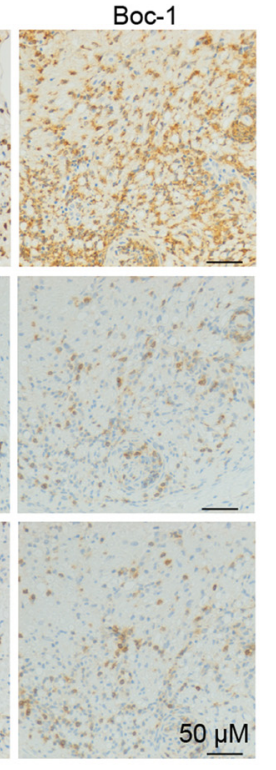

1 Control
Boc-1

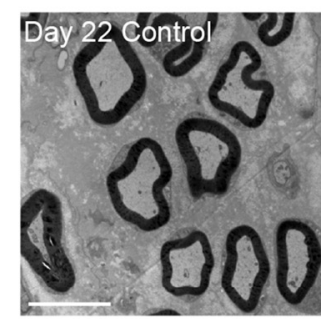

Day 22
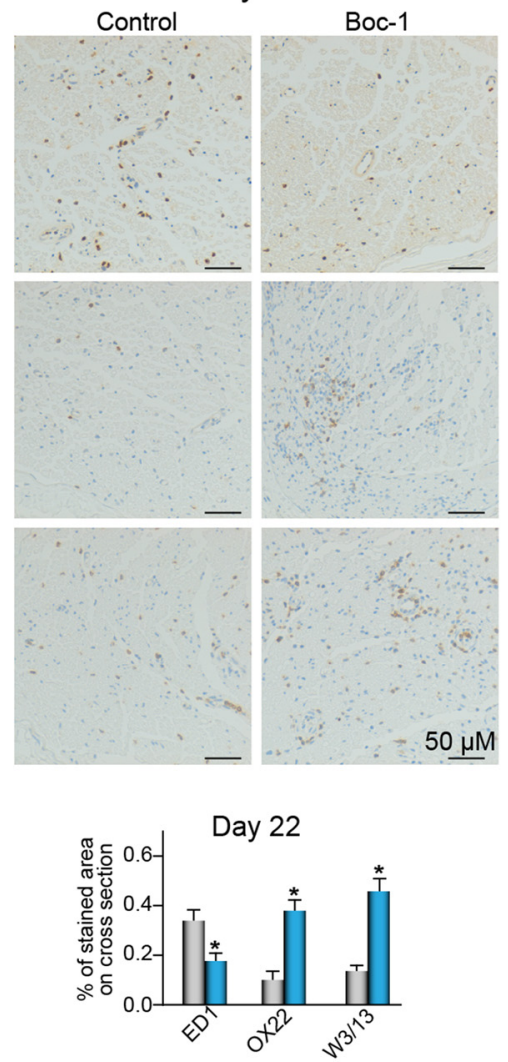

D

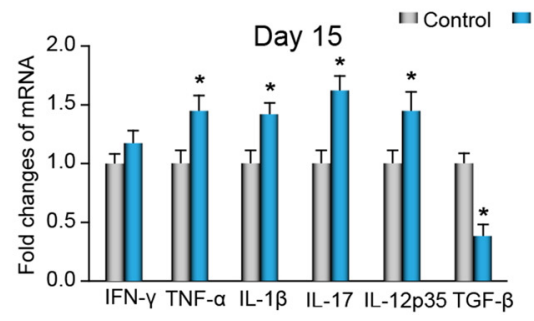

Day 22

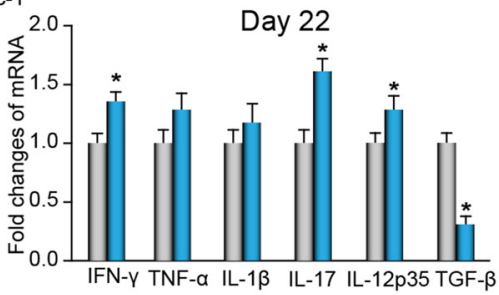

Figure 2. Blockade of endogenous RvD1 exacerbated the progression of EAN. EAN rats were treated with RvD1 receptor ALX antagonist Boc-1 (5 mg/kg/d, i.p.) or vehicle control from day 10 to day 22 after immunization. $\boldsymbol{A}$, Neurological signs of EAN and body weight were monitored daily $(n=6)$. $\boldsymbol{B}$, Sciatic nerves of EAN rats were removed at day 15 and day 22 for electron microscopy analysis and representative electron micrographs are shown. Arrows indicate the axon demyelination $(n=3)$. Axonal demyelination was evaluated and the percentages of intact and abnormal axons were calculated and compared between groups. $\boldsymbol{C}$, Representative immunohistochemistry staining and semiquantification of inflammatory cell infiltration in the sciatic nerves of EAN rats $(n=3)$. $\boldsymbol{D}$, mRNA levels of IFN- $\gamma$, TNF- $\alpha$, IL-1 $\beta$, IL-17, TGF- $\beta$, and IL-12p35 were measured in the sciatic nerves of EAN rats $(n=3)$. Representative data from at least two independent experiments are shown. Error bars indicate SEM. ${ }^{*} p<0.05$.

nificantly increased the mRNA levels of the proinflammatory cytokines IL- $\beta$, TNF- $\alpha$, IL-17, and IFN- $\gamma$, but reduced the level of the anti-inflammatory cytokine TGF- $\beta$ in the sciatic nerves of EAN rats at day 15 and day 22 compared with those in the control group (Fig. 2D). Therefore, Boc-1 in EAN rats induced a worse inflammatory response in the PNS. Together, our data show that the suppression of RvD1 function exacerbated EAN, supporting an important contribution of endogenous RvD1 to the recovery of EAN.

Given the protective role of endogenous RvD1 in EAN, we assessed whether exogenous RvD1 can promote EAN recovery. RvD1 was administered from day 10 to day 22 to mimic clinical conditions. RvD1 treatment greatly shortened the disease duration compared with that in the control group (Fig. 3A), which 
A
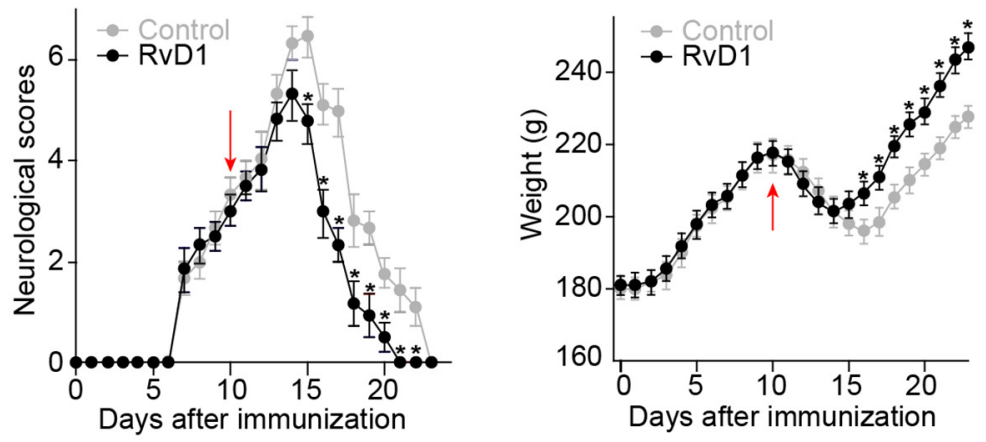

B
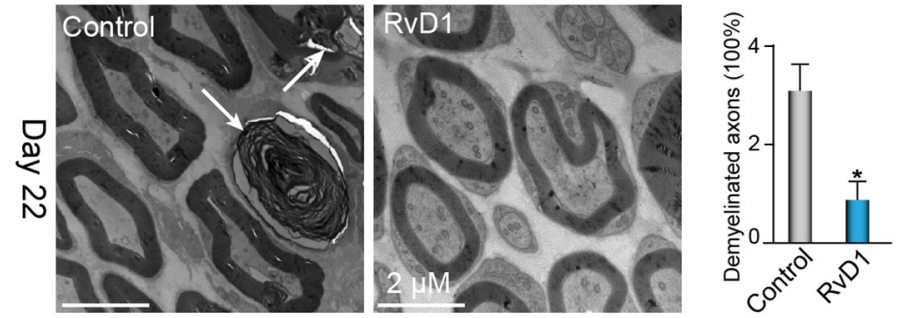

C
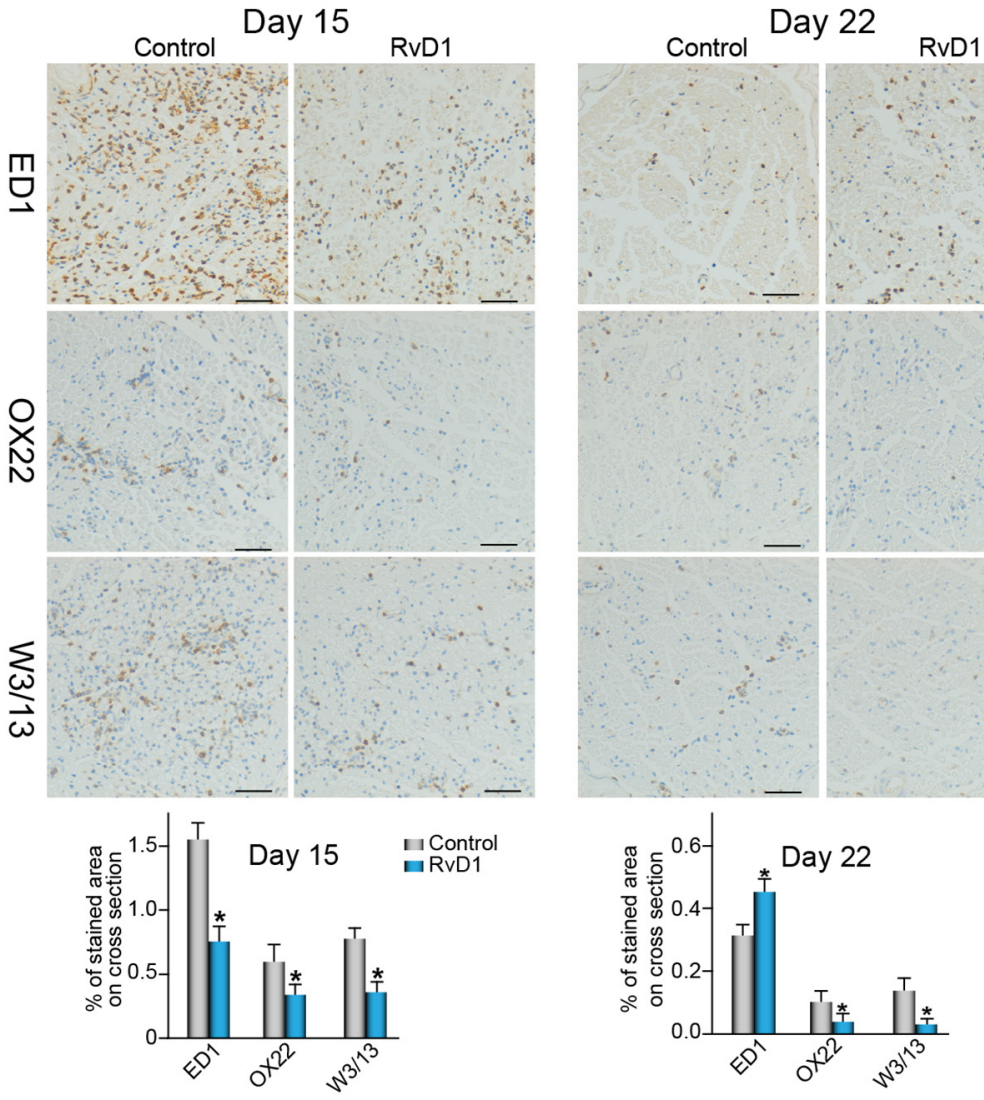

D
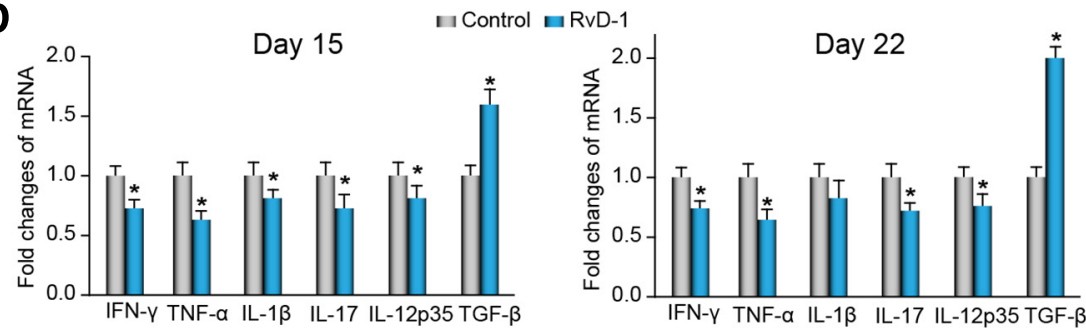

Figure 3. Exogenous RvD1 treatment attenuated EAN. EAN rats were treated with RvD1 (5 $\mu \mathrm{g} / \mathrm{kg} / \mathrm{d}$, i.p.) or vehicle $(0.9 \%$ endotoxin-free saline) from day 10 to day 22 after immunization. $\boldsymbol{A}$, Neurological signs of EAN and body weight were monitored daily $(n=6)$. $\boldsymbol{B}$, Sciatic nerves of EAN rats were removed at day 22 for electron microscopy analysis and representative electron micrographs are shown. Arrows indicate axon demyelination $(n=3)$. C, Representative immunohistochemistry staining and suggests its role in promoting EAN recovery. Furthermore, weight loss was less pronounced in RvD1-treated EAN rats than in the control group, indicating a less severe disease course (Fig. 3A). In addition, sciatic nerves from RvD1-treated EAN rats showed fewer demyelinated fibers compared with those in the control group (Fig. 3B). Therefore, therapeutic exogenous RvD1 treatment promoted PNS repair in EAN rats. Furthermore, exogenous RvD1 significantly reduced the accumulation of $\mathrm{T}\left(\mathrm{W} 3 / 13^{+}\right)$and $\mathrm{B}$ $\left(\mathrm{OX} 22^{+}\right)$lymphocytes at day 15 and day 22 in the sciatic nerves of EAN rats (Fig. $3 C)$. Notably, RvD1 treatment significantly reduced the accumulation of macrophages $\left(\mathrm{ED1}^{+}\right)$at day 15 , but increased this effect at day 22, in the sciatic nerves of EAN rats (Fig. 3C). In parallel, RvD1 treatment markedly reduced the mRNA levels of the proinflammatory cytokines IL- $\beta$, TNF- $\alpha$, IL- 17 , and IFN- $\gamma$, but increased the level of the anti-inflammatory cytokine TGF- $\beta$, in the sciatic nerves of EAN rats at day 15 and day 22 compared with those in the control group (Fig. 3D). Therefore, exogenous RvD1 in EAN rats induced an alleviative inflammation in the PNS. Therefore, our results show that exogenous RvD1 alleviates EAN.

Collectively, our data indicate that endogenous and exogenous $\mathrm{RvD} 1$ promotes local inflammation resolution, reduces peripheral nerve damage, and promotes the recovery of EAN rats.

\section{RvD1 increases anti-inflammatory macrophages and Treg cells in the sciatic nerves of EAN rats}

The self-limitation of EAN is associated with increases in anti-inflammatory macrophages and Treg cells in its remission phase (Meyer zu Hörste et al., 2014); therefore, we sought to determine the role of RvD1 in inducing anti-inflammatory macrophages and Treg cells in the sciatic nerves of EAN rats.

In EAN rats, $\mathrm{CD}_{163}{ }^{+}$macrophages have been identified as having an antiinflammatory phenotype (Fujita et al., 2010; Zhang et al., 2010). We observed that the counts of $\mathrm{CD}_{163^{+}}$macrophages in the sciatic nerves of EAN rats on day 22 were reduced by Boc-1, but were induced

$\leftarrow$

semiquantification of inflammatory cell infiltration in the sciatic nerves of EAN rats $(n=3)$. D, mRNA levels of IFN- $\gamma$, TNF- $\alpha$, IL-1 $\beta$, IL-17, TGF- $\beta$, and IL-12p35 were measured in the sciatic nerves of EAN rats $(n=3)$. Representative data from at least two independent experiments are shown. Error bars indicate SEM. ${ }^{*} p<0.05$. 
by $\mathrm{RvD1}$ (Fig. $4 A$ ), suggesting that RvD1 is important for the induction of anti-inflammatory macrophages in EAN rats. Further double labeling of CD163 and ED1 (CD68) showed that almost all $\mathrm{CD}_{163^{+}}$cells were double labeled with ED1, which proved that $\mathrm{CD}_{163^{+}}$cells were a subpopulation of $\mathrm{ED}^{+}$ macrophages. In addition, $\mathrm{CD}_{16} 3^{+} \mathrm{ED}^{+}$anti-inflammatory macrophages showed very similar distribution patterns to the single-labeled $\mathrm{CD}_{163}{ }^{+}$cells and their numbers were reduced by Boc-1, but induced by RvD1 as well (Fig. 4B). We further determined the accumulation of $\mathrm{CD} 4^{+} \mathrm{Foxp}^{+}$Treg cells in the sciatic nerves of EAN rats after Boc-1 or RvD1 treatment by flow cytometry. Similarly, Boc-1 greatly decreased, but RvD1 increased, the percentages and numbers of Treg cells in EAN sciatic nerves on day 22 compared with their respective controls (Fig. 4B). However, the $\mathrm{CD} 4^{+} \mathrm{Foxp}^{+}$Treg cell counts in the inguinal lymph nodes and spleens of EAN rats remained comparable after Boc-1 or $\mathrm{RvD} 1$ treatment compared with those in the control groups (Fig. 4C), indicating that RvD1 may have no significant effects on Treg cells in lymph nodes.

Together, our results suggest that RvD1 increases the counts of Treg cells and anti-inflammatory $\mathrm{CD} 163^{+}$macrophages in the sciatic nerves of EAN rats, which may contribute to local inflammation resolution in EAN.

\section{RvD1 induces TGF- $\beta$ to promote inflammation resolution in EAN rats}

We sought to understand the mechanisms underlying RvD1promoted inflammation resolution in EAN. Given the essential contribution of TGF- $\beta$ to promoting the self-limitation of EAN and to inducing Treg cells (Shen et al., 2015), we assessed whether RvD1 promotes EAN resolution via TGF- $\beta$. We found that the mRNA and protein level of TGF- $\beta$ was reduced by Boc- 1 (from day 10 to day 22), but increased by RvD1 (from day 10 to day 22), in the sciatic nerves of EAN rats on day 22 compared with those in the control group (Figs. 2D, 3D, 5A). Therefore, the changes in TGF- $\beta$ expression in EAN rats after Boc-1 or RvD1 treatment were consistent with changes in disease severity, Treg cell counts, and anti-inflammatory macrophage numbers, indicating a potential role of TGF- $\beta$ in RvD1-promoted EAN resolution.

To confirm the contributions of TGF- $\beta$ to RvD1-promoted EAN resolution, SD-208 was used to suppress TGF- $\beta$ signaling. SD-208 or vehicle was administered alone or with RvD1 (from day 10 to day 22) to EAN rats. In both the SD-208 alone and RvD1 + SD-208 groups, EAN rats showed much more severe neurological scores and significantly prolonged disease duration, not only compared with the RvD1 + vehicle group, but also compared with the vehicle-alone group (Fig. $5 B$ ), suggesting that the inhibition of TGF- $\beta$ signaling not only abolished the exogenous RvD1 effects, but also may suppress endogenous RvD1 functions. Moreover, sciatic nerves from the RvD1 + SD-208 groups showed more demyelinated fibers without remyelination at both day 15 and day 22 compared with that from RvD1 + vehicle groups or vehicle-alone groups (Fig. 5C), indicating more severe PNS damage in EAN rats by disease peak and recovery.

Furthermore, we analyzed the effects of SD-208 on local inflammatory cell accumulation in the sciatic nerves of RvD1-treated EAN rats. In the RvD1 + SD-208 group, the accumulation of T $\left(\mathrm{W} 3 / 13^{+}\right)$ and $\mathrm{B}\left(\mathrm{OX} 22^{+}\right)$lymphocytes in sciatic nerves was markedly increased at day 15 and day 22 compared with that in the RvD1 + vehicle group or vehicle-alone group, indicating a deteriorated inflammation (Fig. 5D). However, the accumulation of macrophages $\left(\mathrm{EDl}^{+}\right)$in sciatic nerves was significantly increased at day 15 , but reduced at day 22 , in the $\mathrm{RvD} 1+\mathrm{SD}-208$ group compared with that in the $\mathrm{RvD} 1$ + vehicle group or the vehicle-alone group, supporting a delayed inflammation resolution (Fig. 5D). Correspondingly, the mRNA levels of the proinflammatory cytokines IL- $\beta$ and IL-17 in sciatic nerves were significantly higher at day 15 and day 22 in the RvD1 + SD-208 group compared with that in the RvD1 + vehicle group or the vehicle-alone group (Fig. 5E).

In addition, SD-208 not only abolished exogenous RvD-1increased Treg cell counts in sciatic nerves of EAN rats, but also reduced the numbers of Treg cells to levels comparable to that in Boc-1-treated EAN rats (Fig. $5 F$ ), indicating that RvD1 increased Treg cell counts via TGF- $\beta$ in the sciatic nerves of EAN rats. SD-208 also reduced RvD-1-increased CD163 ${ }^{+}$cell counts (Fig. $5 G$ ). Further double labeling of CD163 and ED1 presented comparable IR area and distribution pattern with the single labeling of $\mathrm{CD} 163$ and the numbers of $\mathrm{CD} 163^{+} \mathrm{ED}^{+}$anti-inflammatory macrophages were significantly reduced by SD-208 as well (Fig. $5 H$ ). Collectively, these results suggest that RvD1 induces Treg cells and promotes inflammation resolution and disease recovery via TGF- $\beta$ in EAN rats.

\section{RvD1 promotes apoptotic cell phagocytosis to induce TGF- $\beta$ in macrophages}

We next sought to explore the mechanisms underlying RvD1induced TGF- $\beta$ in EAN rats. We first investigated the major cellular sources of TGF- $\beta$-level changes in EAN rats after RvD1 signaling interference. Macrophages and Treg cells are two major cellular sources of TGF- $\beta$ in EAN (Zhu et al., 2004; Yun et al., 2007 ), but the inhibition of TGF- $\beta$ signaling abolished RvD1induced Treg cell counts increase, suggesting that Treg cells might not be the major cellular source for RvD-1-induced TGF- $\beta$ in the EAN. Moreover, the RvD1 receptor ALX is mainly expressed on macrophages in the sciatic nerves of EAN rats (Fig. $1 C$ ), so we focused on macrophages. We found that Boc-1 administration to EAN rats (from day 10 to day 22) significantly reduced the counts of $\mathrm{CD} 68^{+} \mathrm{TGF}-\beta^{+}$cells in sciatic nerves compared with that in the control group (Fig. 6A). Conversely, exogenous RvD1 (from day 10 to day 22) greatly increased the numbers of $\mathrm{CD} 68^{+}$TGF- $\beta^{+}$cells in sciatic nerves compared with the controls (Fig. 6A). Therefore, the RvD-1-induced changes in the TGF- $\beta$ level in macrophages were consistent with its effects on the changes in the total TGF- $\beta$ level, disease severity, Treg-cell counts, and anti-inflammatory macrophage numbers in EAN, suggesting a major contribution of macrophages to RvD1induced TGF- $\beta$ in EAN rats.

We then investigated whether RvD1 can induce TGF- $\beta$ directly in macrophages in vitro. Peritoneal macrophages were incubated with RvD1 for $24 \mathrm{~h}$ and TGF- $\beta$ levels were not induced at either the mRNA or protein levels (Fig. $6 B$ ), indicating an indirect effect. Given the high expression of TGF- $\beta$ after apoptotic cell phagocytosis by phagocytes (Huynh et al., 2002) and its known function in promoting the macrophage engulfment of dying cells, we speculated that RvD1 may induce macrophage TGF- $\beta$ upregulation by promoting dying cell clearance. RvD1 enhanced the peritoneal macrophage phagocytosis of apoptotic Jurkat cells in a dose-dependent manner (Fig. $6 C$ ). In dying cells, RvD1 upregulated the TGF- $\beta$ mRNA level in peritoneal macrophages and increased TGF- $\beta$ protein levels in cell culture supernatants (Fig. $6 D)$. Furthermore, this effect was abolished by Cyclophilin D, which inhibited RvD1-promoted dying cell clearance by peritoneal macrophages (Fig. $6 C, D$ ), indicating that RvD1 upregulated TGF- $\beta$ by promoting dying cell clearance in macrophages.

In addition, the phagocytosis of apoptotic cells reprograms macrophages to an anti-inflammatory status, which is character- 
A

CD163 staining

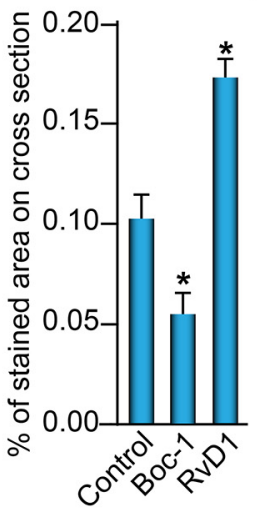

B
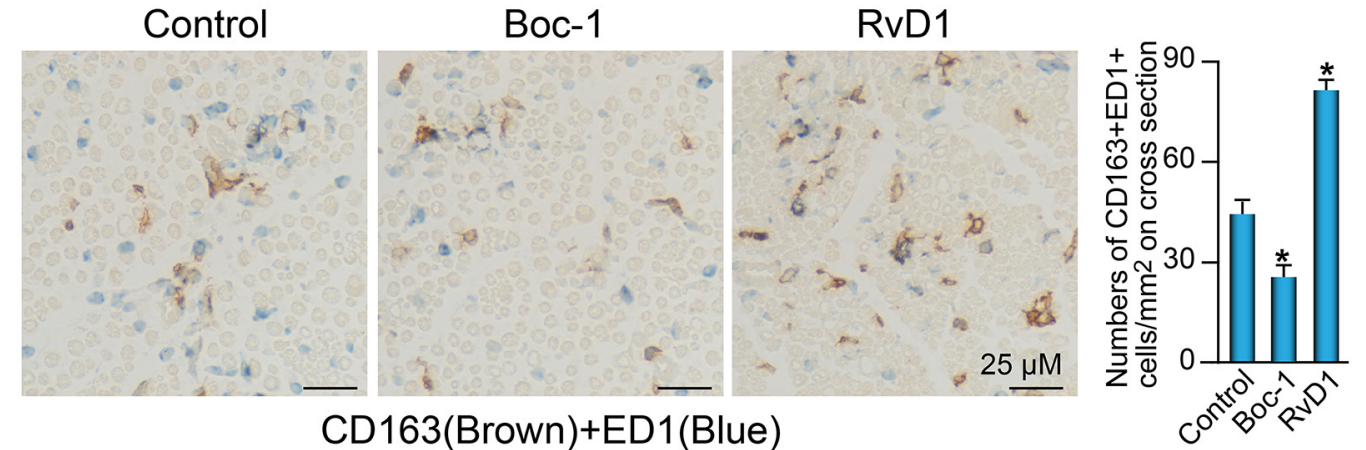

\section{Day 22 Sciatic nerve}

C
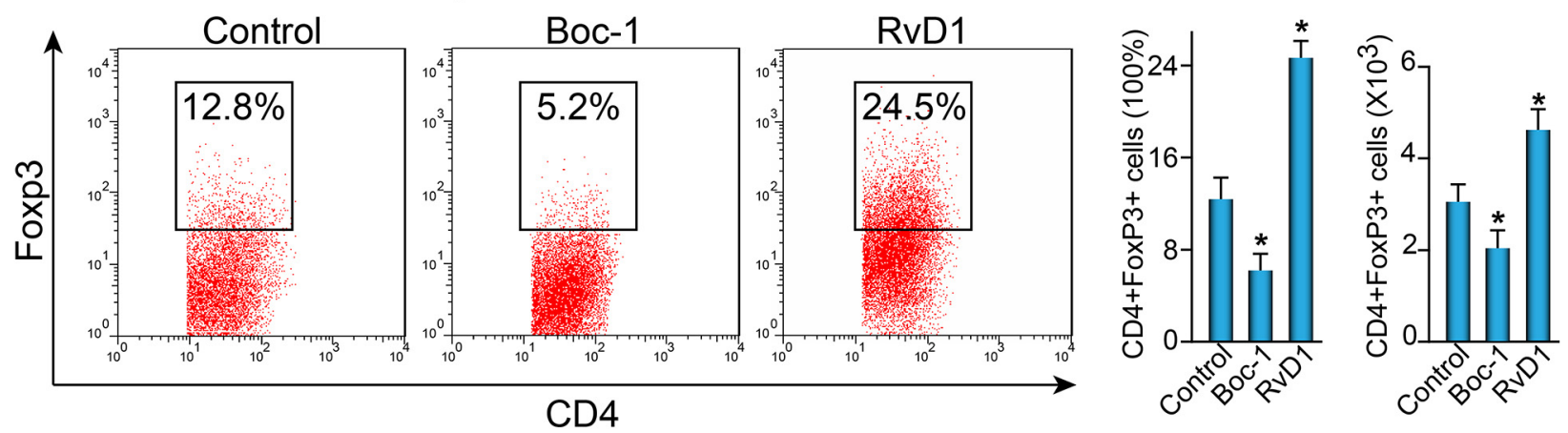

D

Day 22 inguinal lymph node
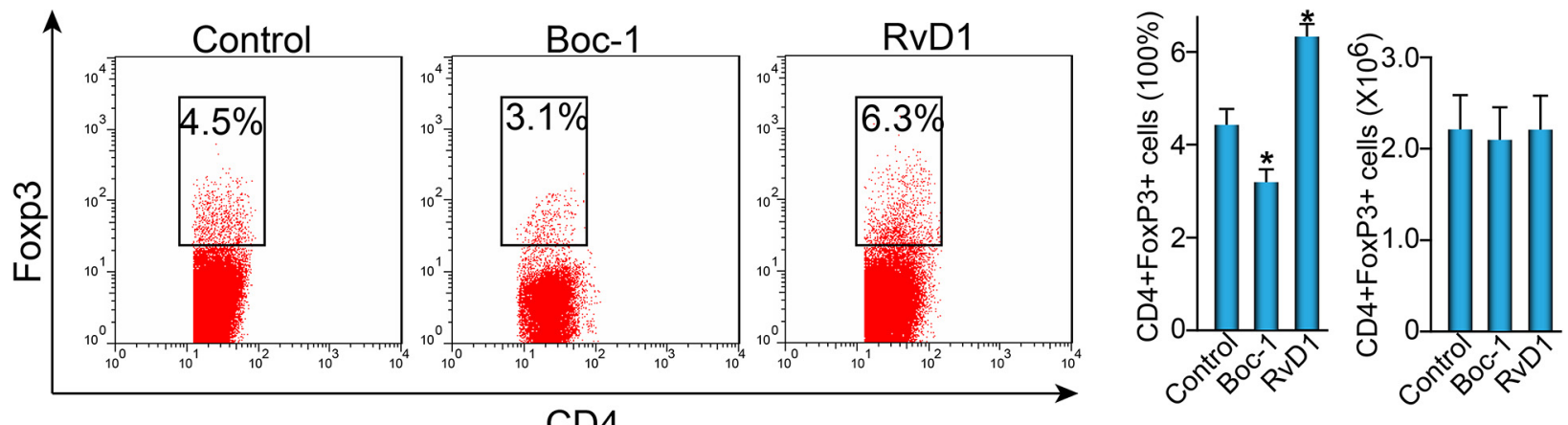

Day 22 spleen
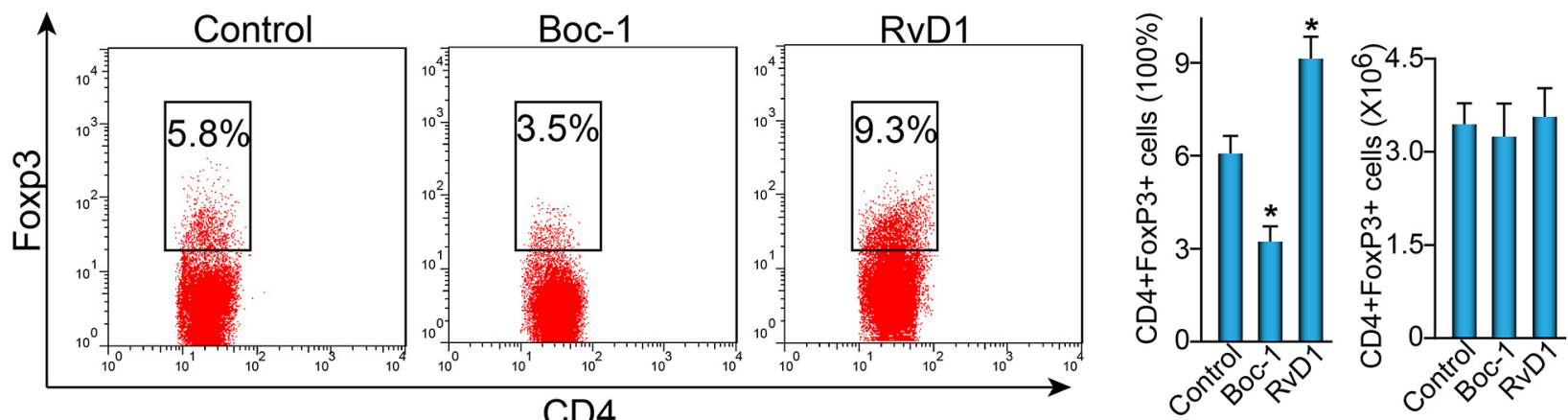

Figure 4. RvD1 increased anti-inflammatory macrophages and Treg cells in the sciatic nerves of EAN rats. EAN rats were treated with RvD1 (5 $\mu \mathrm{g} / \mathrm{kg} / \mathrm{d}$, i.p.), Boc-1 ( $5 \mathrm{mg} / \mathrm{kg} / \mathrm{d}, \mathrm{i} . \mathrm{p}$.$) , or saline from$ day 10 to day 22 after immunization. The accumulation of $C D 163^{+}$anti-inflammatory macrophages and $C D 4^{+}$Foxp3 ${ }^{+}$Treg cells was analyzed on day $22 . A$, Semiquantification of $C D 163^{+}$ anti-inflammatory macrophages in the sciatic nerves of EAN rats $(n=3) \cdot \boldsymbol{B}$, Representative immunohistochemical double immunostaining and quantifications of $C D 163^{+}$ED1 $1^{+}$anti-inflammatory macrophages on cross-sections of the sciatic nerves $(n=3)$. $\boldsymbol{C}, \boldsymbol{D}$, Representative flow cytometric dot plots of $\mathrm{CD}^{+}{ }^{+}$Foxp $3^{+}$Treg cells in the sciatic nerves $(\boldsymbol{C}, n=3)$, lymph nodes $(\boldsymbol{D}, n=3)$, and spleens $(\boldsymbol{D}, n=3)$ of EAN rats as measured by flow cytometry. Representative data from at least two independent experiments are shown. Error bars indicate SEM. ${ }^{*} p<0.05$. 
A

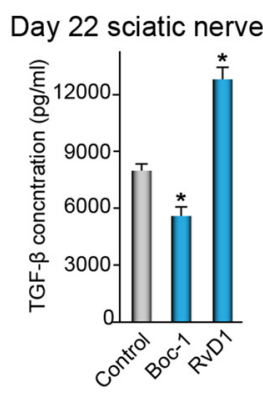

C
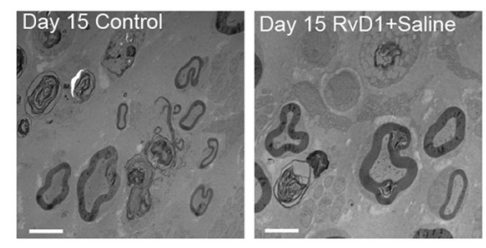

Day 15
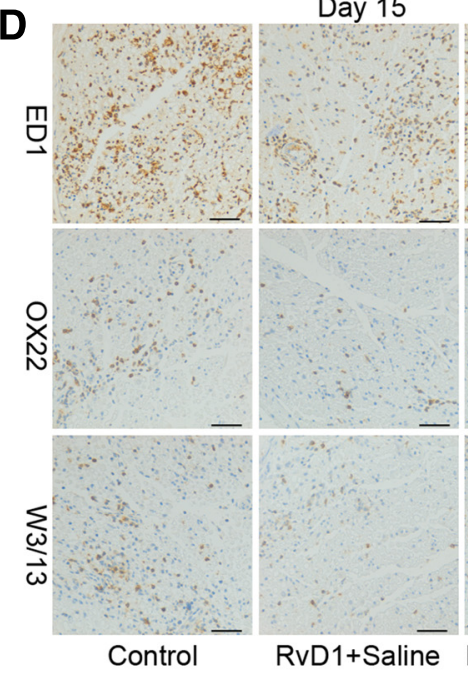

B

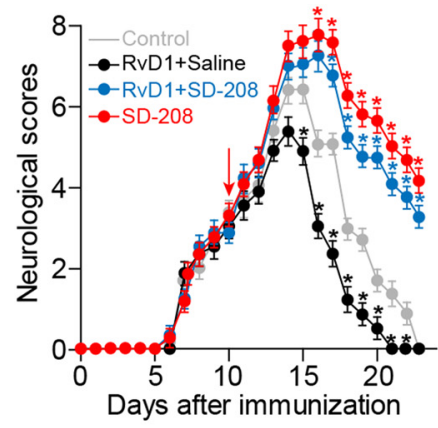

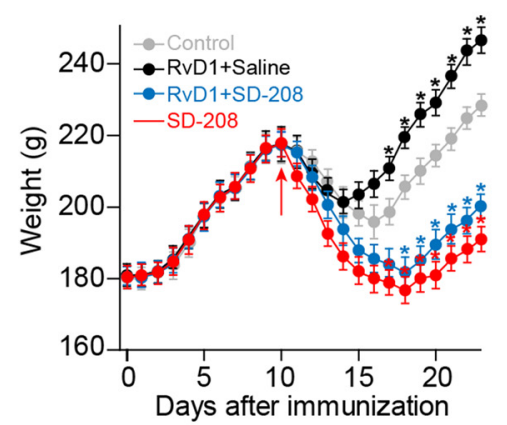
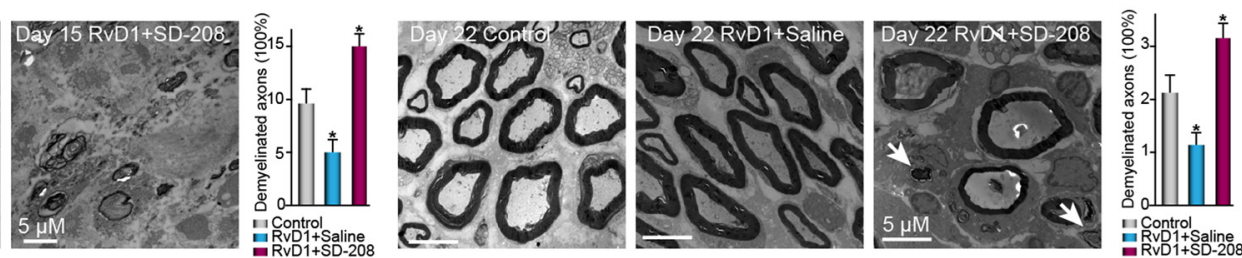

Day 22
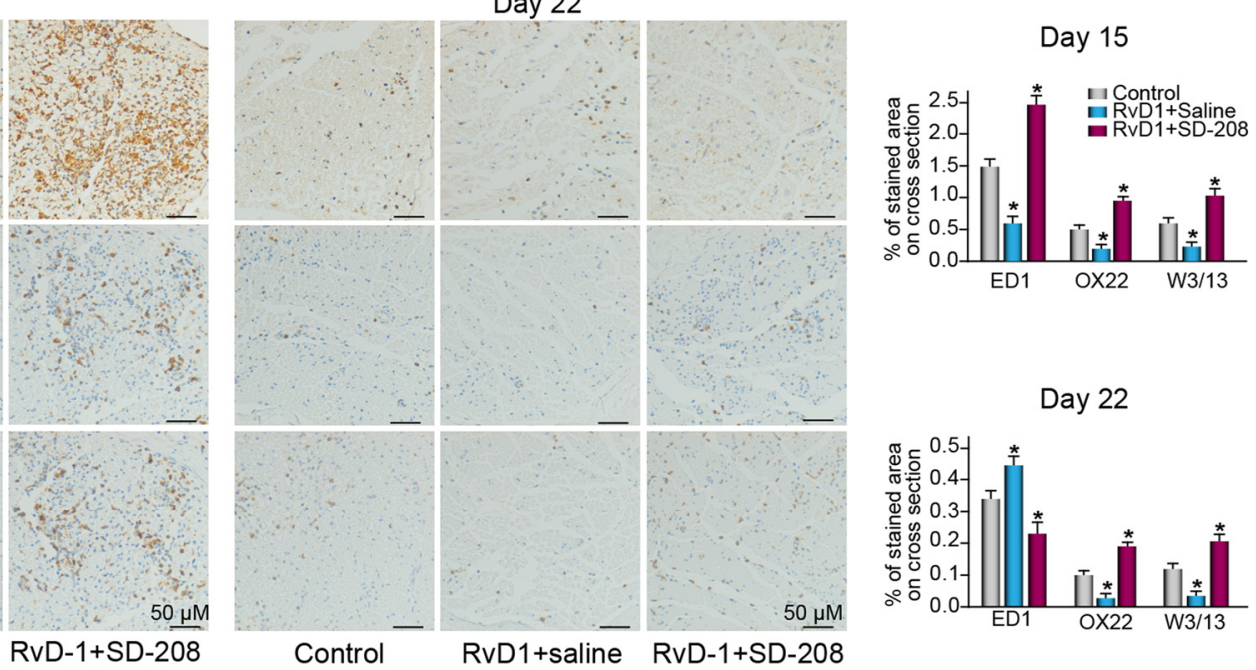

E
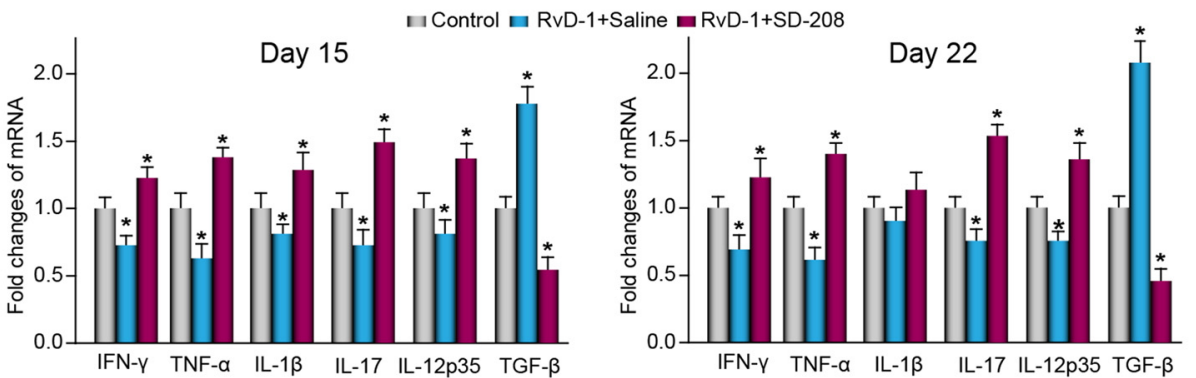

F

Day 22 Sciatic nerve

Day 22
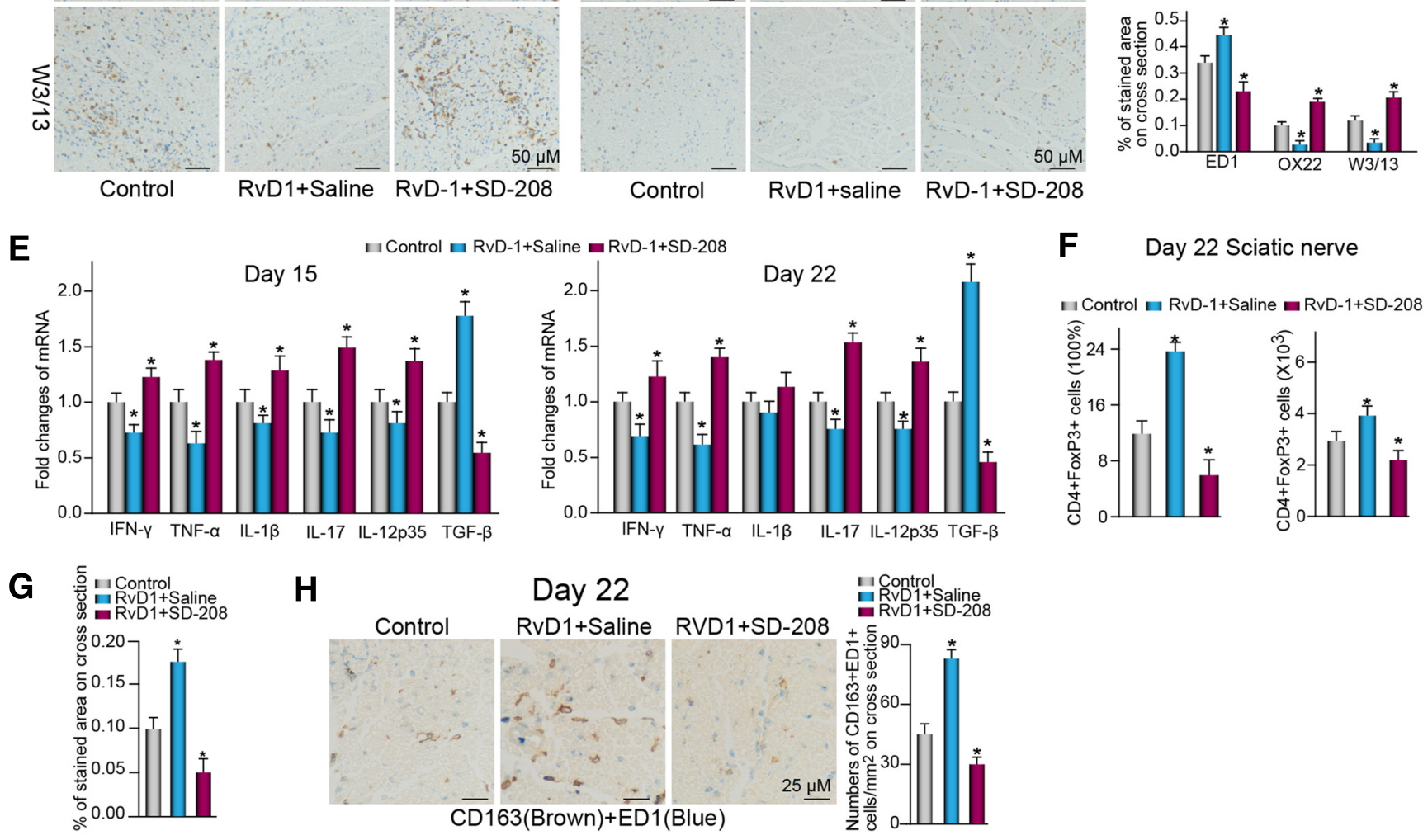

Figure 5. RvD1 promoted inflammation resolution and disease recovery via TGF- $\beta$ in EAN rats. $A$, Protein level of TGF- $\beta$ in the sciatic nerves of EAN rats on day 22 that were treated with RvD1 $(5 \mu \mathrm{g} / \mathrm{kg} / \mathrm{d})$, Boc-1 $(5 \mathrm{mg} / \mathrm{kg} / \mathrm{d})$, or saline from day 10 to day 22 after immunization was measured by ELISA $(n=3)$. $\boldsymbol{B}-\boldsymbol{H}$, EAN rats were treated with saline alone (control), RvD1 (5 $\mu \mathrm{g} / \mathrm{kg} / \mathrm{d}$, i.p.) together with saline or the TGF- $\beta$ receptor antagonist SD- $208(20 \mathrm{mg} / \mathrm{kg} / \mathrm{d}$, i.p.), or SD-208 alone from day 10 to day 22 after immunization. Rats were monitored daily for neurological signs of EAN and body weight $(\boldsymbol{B}, n=6)$. $\boldsymbol{C}$, Sciatic nerves from EAN rats on day 15 and day 22 were analyzed by electron microscopy; arrows indicate the axon demyelination ( $n=3)$. $\boldsymbol{D}$, Representative immunohistochemistry staining and semiquantification of inflammatory cell infiltration in EAN sciatic nerves $(n=3)$. $\boldsymbol{E}$, mRNA levels of IFN- $\gamma$, (Figure legend continues.) 
A

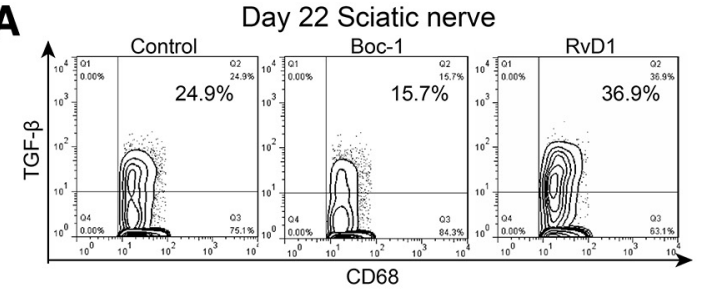

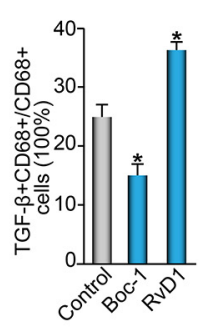

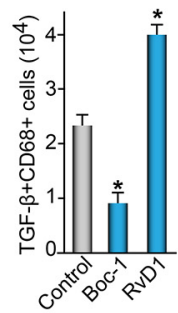

B

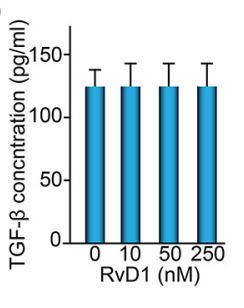

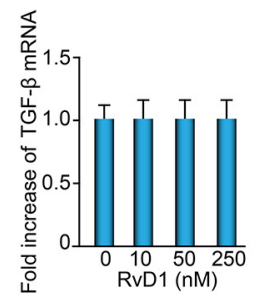
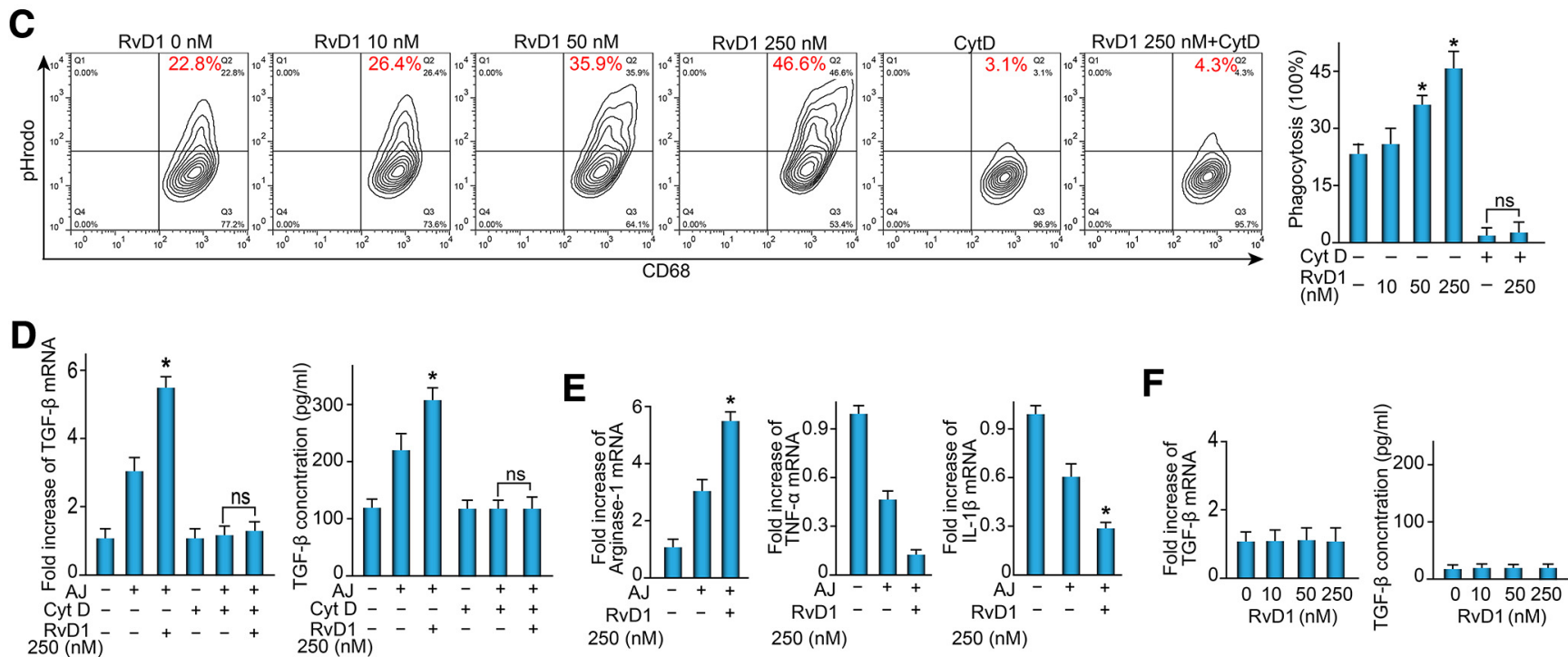

Figure 6. RvD1 enhanced apoptotic cell phagocytosis to induce TGF- $\beta$ in macrophages. A, Protein level of TGF- $\beta$ in $C D 68^{+}$macrophages from the sciatic nerves of EAN rats that were treated with $\operatorname{RvD1}(5 \mu \mathrm{g} / \mathrm{kg} / \mathrm{d}$, i.p.), Boc-1 (5 mg/kg/d, i.p.), or saline from day 10 to day 22 after immunization was analyzed by flow cytometry $(n=3)$. B, Rat peritoneal macrophages were incubated with RvD1 for $24 \mathrm{~h}$ in vitro and the TGF- $\beta$ protein level in culture supernatants and the mRNA level in macrophages were measured by ELISA and RT-PCR, respectively $(n=3)$. C, Rat peritoneal macrophages were treated with RvD1 together with CytD $(2 \mu \mathrm{m})$ or control for $24 \mathrm{~h}$ and fed with pHrodo-labeled apoptotic Jurkat cells for $1 \mathrm{~h}$ and the macrophage phagocytosis of apoptotic Jurkat cells was measured by flow cytometry $(n=3)$. D, Rat peritoneal macrophages were incubated with apoptotic Jurkat cells (AJ), RvD1 ( $250 \mathrm{~nm})$, CytD ( $2 \mu \mathrm{M})$, or control for $24 \mathrm{~h}$ and the TGF- $\beta$ protein level in culture supernatants and the mRNA level in macrophages were measured by ELISA and RT-PCR, respectively $(n=3)$. $\boldsymbol{E}$, Rat peritoneal macrophages were incubated with RvD1 ( $250 \mathrm{~nm})$ in the presence of apoptotic Jurkat cells (AJ) in vitro for $24 \mathrm{~h}$ and the mRNA levels of Arginase-1, TNF- $\alpha$, and IL- $1 \beta$ in macrophages were then analyzed by RT-PCR $(n=3)$. $\boldsymbol{F}$, Different concentrations of RvD1 were directly added to Jurkat cell cultures and incubated for $24 \mathrm{~h} ;$ TGF- $\beta$ production was not changed. Representative data from at least two independent experiments are shown. Error bars indicate SEM. ${ }^{*} p<0.05$.

ized by a high expression of TGF- $\beta$ and arginase- 1 , as well as a low expression of TNF- $\alpha$ and IL- $1 \beta$. We also measured the expression of several other cytokines and found that RvD1 increased arginase-1, but reduced TNF- $\alpha$ and IL- $1 \beta$, in peritoneal macrophages during dying cell clearance (Fig. $6 E$ ), suggesting an antiinflammatory phenotype. In addition, to exclude the possible effect of RvD1 on live Jurkat cells in our system, RvD1 was added to Jurkat cell culture, incubated for $24 \mathrm{~h}$, and no changes in TGF- $\beta$ production were observed (Fig. $6 F$ ). Therefore, these results suggest that RvD1 enhances the macrophage phagocytosis of dying cells to induce anti-inflammatory macrophages that express high levels of TGF- $\beta$.

(Figure legend continued.) TNF- $\alpha$, IL-1 $\beta$, IL-17, IL-12p35, and TGF- $\beta$ were measured in the sciatic nerves of EAN rats $(n=3)$. $\boldsymbol{F}$, Accumulation of $\mathrm{CD}^{+}$Foxp $3^{+}$Treg cells in the sciatic nerves of EAN on rats day 22 was measured $(n=3)$. G, Semiquantification of anti-inflammatory macrophages $\left(\mathrm{CD}_{163^{+}}\right)$in sciatic nerves of EAN rats on day $22(n=3)$. $\boldsymbol{H}$, Representative immunohistochemical double-immunostaining and quantifications of $\mathrm{CD}_{1} 63^{+} \mathrm{ED} 1^{+}$antiinflammatory macrophages on cross sections of the sciatic nerves $(n=3)$. Representative data from at least two independent experiments are shown. Error bars indicate SEM. ${ }^{*} p<0.05$.

\section{RvD1 promotes the macrophage phagocytosis of apoptotic} cells in the PNS of EAN rats

We investigated whether RvD1 enhances the engulfment of apoptotic T cells by macrophages in EAN rats. Flow cytometry was used to detect in vivo phagocytosis and $\mathrm{CD}^{+}{ }^{+} \mathrm{CD} 68^{+}$permeabilized cells were identified as macrophages with ingested T cells. Boc-1 treatment (from day 10 to day 22) significantly reduced the number of $\mathrm{CD}^{+} \mathrm{CD}^{+} 8^{+}$cells in the sciatic nerves of EAN rats compared with controls (Fig. $7 A$ ). Conversely, exogenous RvD1 administration (from day 10 to day 22) greatly enhanced the number of $\mathrm{CD}_{3}{ }^{+} \mathrm{CD} 68^{+}$cells in EAN sciatic nerves (Fig. $7 B$ ). Correspondingly, the accumulation of apoptotic T lymphocytes in the sciatic nerves of EAN rats was greatly increased after Boc-1 treatment, but significantly reduced after RvD1 administration by flow cytometry (Fig. 7C). This observation was confirmed by TUNEL staining in the sciatic nerves of EAN rats after Boc-1 or RvD1 administration (Fig. 7D). In addition, RvD1 treatment did not increase Jurkat-cell or spleen T-cell apoptosis directly in vitro, indicating that the accumulation of apoptotic $\mathrm{T}$ cells in EAN rats after Boc-1 or RvD1 treatment is not due to an increase in T-cell apoptosis by RvD1 (Fig. 7E). Therefore, RvD1 promotes the clearance of dying $\mathrm{T}$ cells by macrophages in EAN rats. 

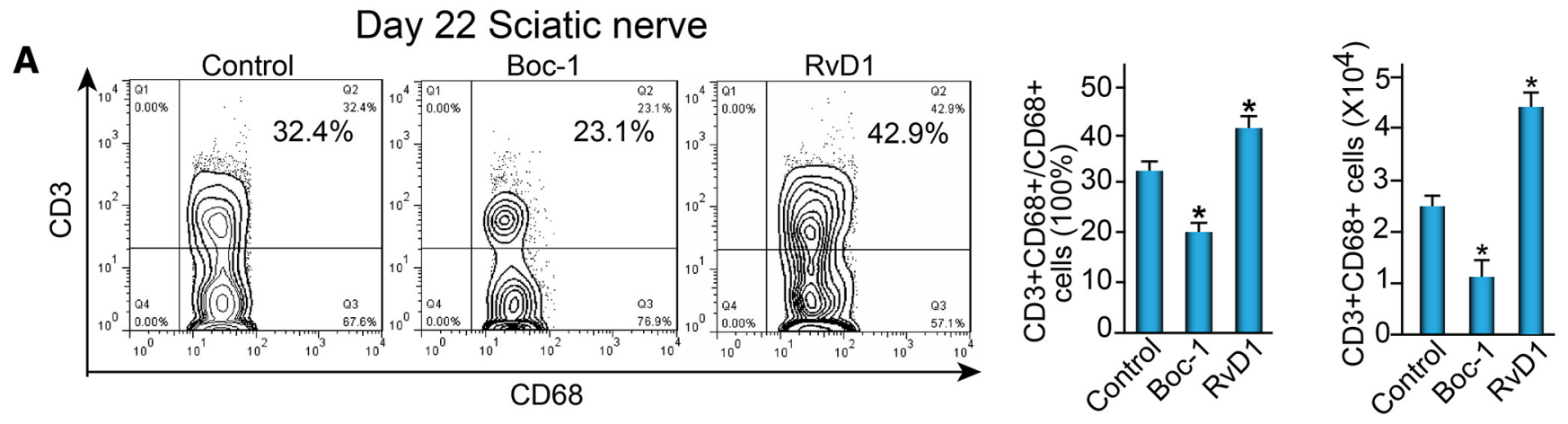

B

Day 22 Sciatic nerve
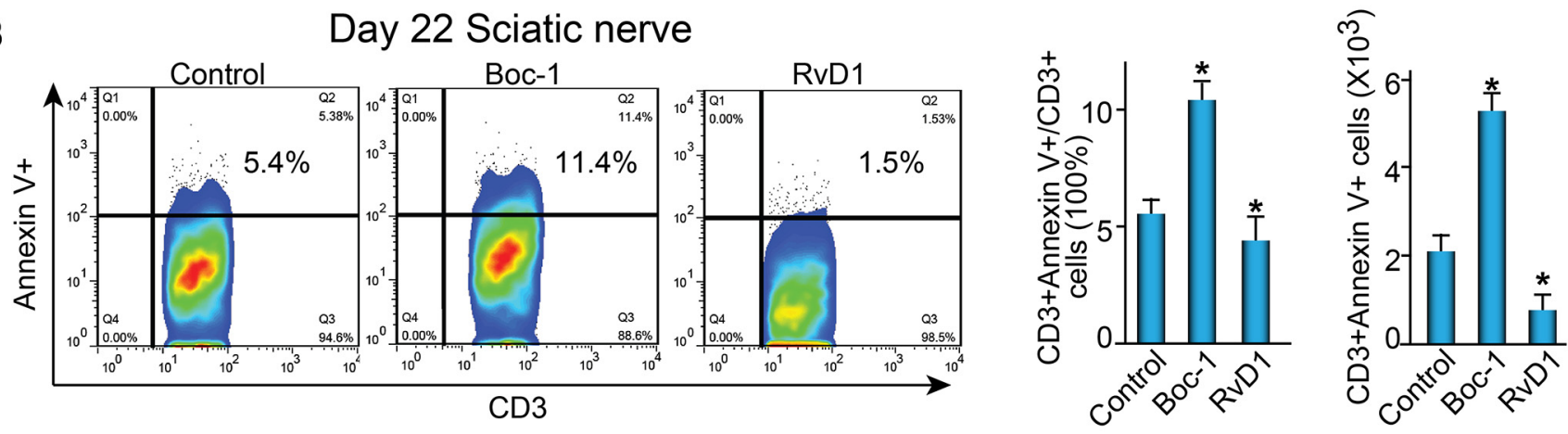

C

Day 22 Sciatic nerve
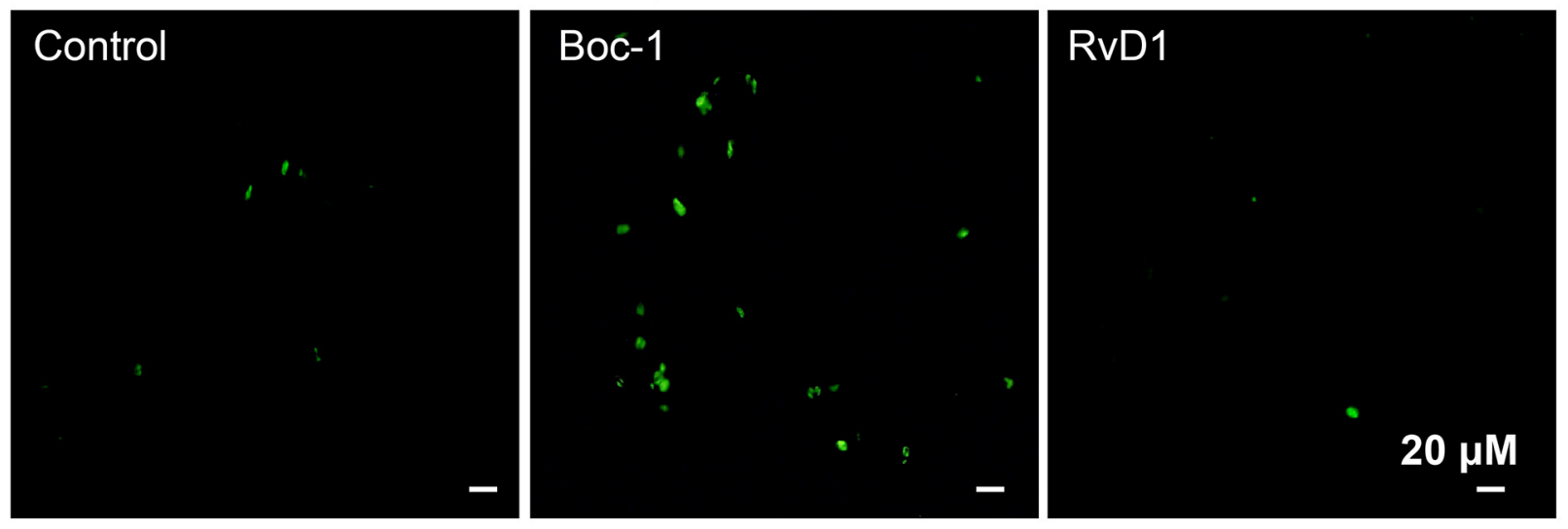

D

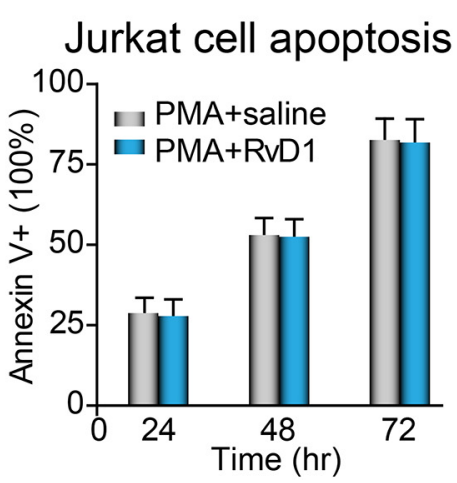

E Spleen T cell apoptosis

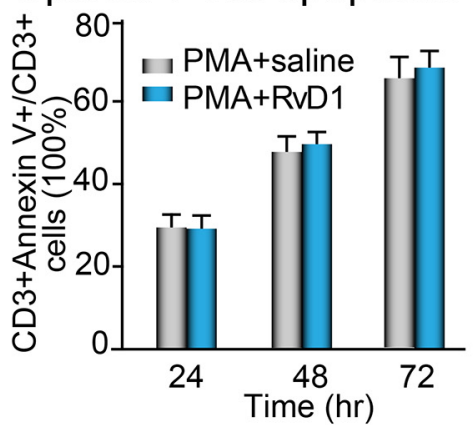

Figure 7. RvD1 promotes macrophage phagocytosis of apoptotic T cells in EAN sciatic nerves. EAN rats were treated with RvD1 (5 $\mu \mathrm{g} / \mathrm{kg} / \mathrm{d}$, i.p.), Boc-1 (5 mg/kg/d, i.p.), or saline from day 10 to day 22 after immunization $(n=3)$. EAN sciatic nerves were removed for flow cytometric and TUNEL analysis on day 22 . $\boldsymbol{A}$, Flow cytometry was used to detect the macrophage phagocytosis of apoptotic $\mathrm{T}$ cells in EAN sciatic nerves. $\mathrm{CD}^{+}{ }^{+} \mathrm{CD} 68^{+}$-permeabilized cells were identified as macrophages with ingested $\mathrm{T}$ cells $(n=3)$. $\boldsymbol{B}$, Flow cytometry of apoptotic $\mathrm{T}$ lymphocytes (AnnexinV $\mathrm{CD}^{+}$) accumulation in EAN sciatic nerves $(n=3)$. C, TUNEL staining of apoptotic cell accumulation in the sciatic nerves of EAN rats $(n=3)$. (Figure legend continues.) 


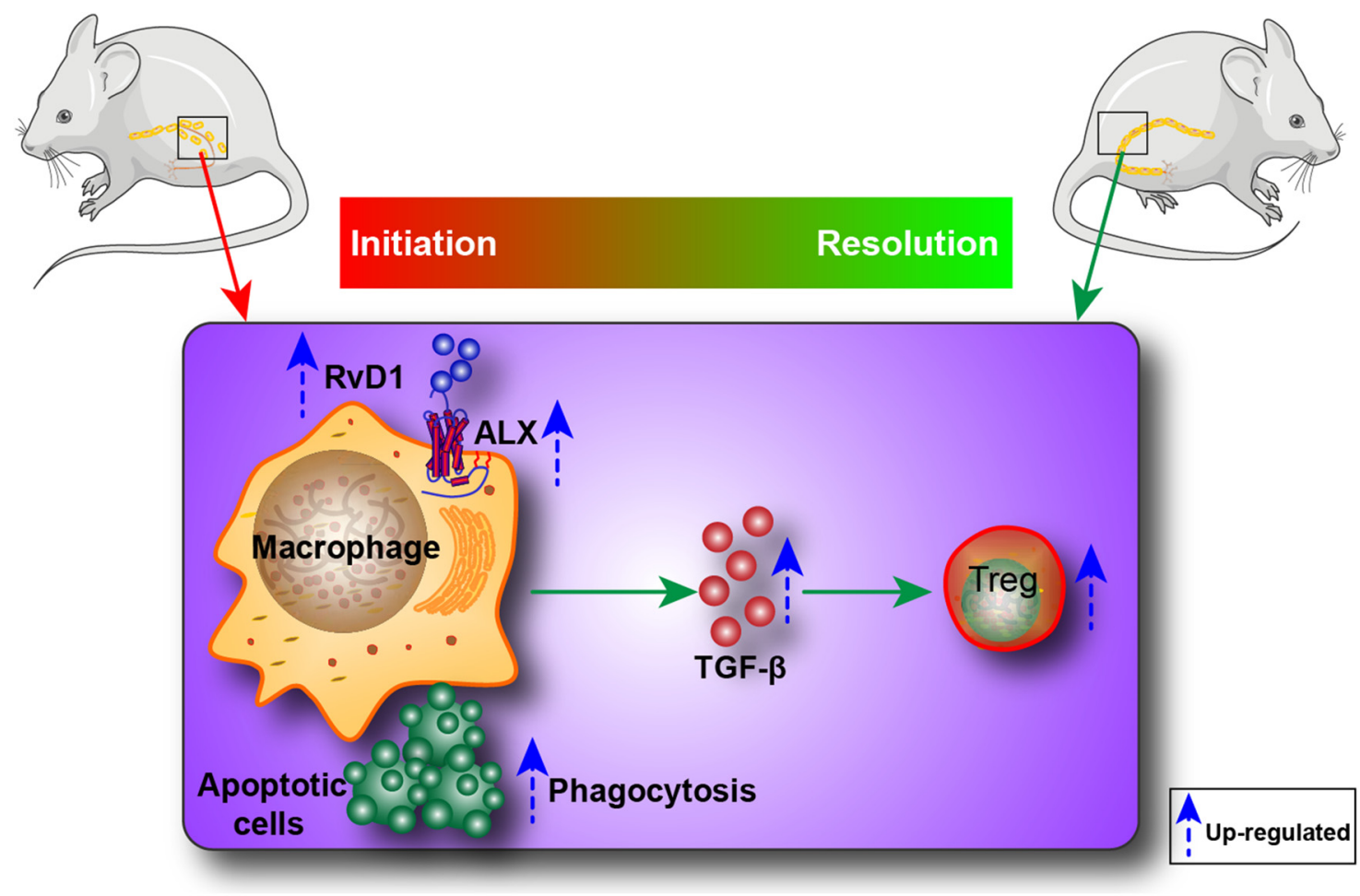

Figure 8. Schematic diagram showing how RvD1 increases the macrophage phagocytosis of apoptotic T cells to induce TGF- $\beta$, promoting inflammation resolution and disease recovery in EAN. RvD1, its synthetic enzyme, and its receptor were greatly increased in the PNS during the recovery stage of EAN. The enhanced RvD1 pathway promoted the macrophage phagocytosis of apoptotic T cells in the PNS, resulting in reduced apoptotic T-cell accumulation and the up-regulation of TGF- $\beta$ by macrophages. The induced TGF- $\beta$ enhanced Treg cell counts and inflammation resolution in the PNS, leading to disease recovery in EAN rats.

\section{Discussion}

The resolution of inflammation has been observed in various autoimmune diseases; however, the underlying mechanisms are largely uncharacterized. Furthermore, there is a critical need to understand endogenous pathways that regulate autoimmune inflammation resolution to provide new perspectives on disease pathogenesis and direct new therapeutic approaches. Here, we have identified a physiological pathway that involves RvD1, apoptotic T-cell clearance, anti-inflammatory macrophages, and TGF- $\beta$ and Treg cells to promote autoimmune inflammation resolution in EAN (Fig. 8). We determined that RvD1, its synthetic enzyme, and its receptor in PNS were greatly increased during the recovery stage of EAN. Endogenous and exogenous RvD1 increased Treg-cell and anti-inflammatory macrophage counts, enhanced inflammation resolution in PNS, and promoted disease recovery in EAN rats. Moreover, the pharmacologic inhibition of TGF- $\beta$ signaling suppressed RvD1-induced Treg cell counts, RvD1-improved inflammation resolution, and disease recovery in EAN rats. Mechanistically, RvD1 promoted the macrophage phagocytosis of apoptotic T cells in the PNS, resulting in reduced apoptotic T-cell accumulation in the PNS, the upregulation of TGF- $\beta$ by macrophages, the induction of

$\leftarrow$

(Figure legend continued.) $\quad$ D, Jurkat cell apoptosis was induced by incubation with PMA (50 $\mathrm{ng} / \mathrm{ml}$ ) together with RvD1 ( $250 \mathrm{~nm}$ ) or control for 24,48 , or $72 \mathrm{~h}$ and then flow cytometry was used to detect cell apoptosis $(n=3)$. $\boldsymbol{E}$, Rat spleen cells were cultured in serum-free RPMI 1640 medium together with RvD1 ( $250 \mathrm{~nm}$ ) or control for 24,48 , or $72 \mathrm{~h}$. Flow cytometry was used to detect $\mathrm{CD}^{+}$T-cell apoptosis $(n=3)$. Representative data from at least two independent experiments are shown. Error bars indicate SEM. ${ }^{*} p<0.05$.
Treg cells, and finally inflammation resolution in EAN rats. Several specific conclusions can be drawn from our data.

This work uncovers an essential role of the RvD1 cascade in enhancing apoptotic T-cell clearance and promoting autoimmune inflammation resolution in EAN. As a Th-cell-mediated autoimmune disease, PNS inflammation in EAN is characterized by the infiltration of autoantigen-specific $\mathrm{T}$ cells, followed by circulating monocytes. Although the pro-resolving activity of RvD1 has been well established in acute inflammation that is characterized by the rapid infiltration of blood neutrophils followed by the infiltration of monocytes, the involvement of RvD1 in the resolution of autoimmune inflammation in EAN remains unknown. In acute inflammation, the production of RvD1 is mainly from neutrophils and macrophages (Sun et al., 2007). Interestingly, we found that the levels of RvD1, its receptor ALX/FPR2, and its key synthetic enzyme 12/15-LOX increased continuously in the PNS after EAN initiation. Moreover, pharmacological blocking of the RvD1 pathway aggravated the inflammation resolution in the PNS of EAN rats, but therapeutic treatment with exogenous RvD1 significantly promoted inflammation resolution in EAN. Therefore, these results reveal the pro-resolving effects of the RvD1 cascade in EAN.

$\mathrm{RvD} 1$ promotes inflammation resolution mainly by enhancing the phagocytosis of apoptotic cells (Krishnamoorthy et al., 2010). In EAN and many other autoimmune inflammatory disorders such as autoimmune hepatitis (Czaja, 2014), experimental autoimmune encephalomyelitis (Wang et al., 2013), experimental autoimmune thyroiditis (Fang et al., 2011), experimental autoimmune anterior uveitis (Jha et al., 2007), and experimental autoimmune arthritis (Pay et al., 2007), although T-cell apoptosis has been well established to contribute to inflammation resolution and disease spontaneous recovery (Orteu et al., 2000; Ariel et 
al., 2006), the mechanisms underlying apoptotic cell clearance are poorly known. In the present study, we found that blocking RvD1 activity strongly decreased the macrophage phagocytosis of apoptotic $\mathrm{T}$ cells and increased apoptotic cell accumulation in the PNS of ENA rats. Conversely, exogenous RvD1 significantly enhanced the macrophage engulfment of apoptotic $\mathrm{T}$ cells and decreased the apoptotic cell accumulation in the PNS of ENA rats, revealing the major contribution of RvD1 to the removal of apoptotic T cells in EAN. However, whether RvD1 also contributes to apoptotic T-cell clearance in other autoimmune disorders remains to be explored.

Our work also revealed that RvD1 promotes the polarization of anti-inflammatory macrophages and thereby induces TGF- $\beta$ production, leading to the inflammation resolution in EAN. The clearance of apoptotic cells induces the secretion of antiinflammatory cytokines from macrophages and thereby promotes a switch to the anti-inflammatory phenotype (Huynh et al., 2002; Titos et al., 2011; Chang et al., 2015). Consistent with these previous observations, we found that the blockage of RvD1 decreased anti-inflammatory macrophage counts because a subpopulation of activated local macrophages in the PNS of EAN and exogenous RvD1 increased the counts. Anti-inflammatory macrophages contribute to inflammation resolution in various diseases (Sindrilaru and Scharffetter-Kochanek, 2013; Italiani and Boraschi, 2014; Chang et al., 2015), including EAN (Zhang et al., 2009a; Zhang et al., 2010). Anti-inflammatory macrophages exert their pro-resolving functions mainly through their secreted cytokines such as IL-10 and TGF- $\beta$ (Zhang et al., 2012; Brunn et al., 2014). Among these cytokines, our data revealed that TGF- $\beta$ has a central role in RvD1-induced EAN resolution because blocking TGF- $\beta$ activity abolished the pro-resolving activity of RvD1 in EAN. As one of the central instigators of the antiinflammatory milieu, TGF- $\beta$ effectively orchestrated inflammation resolution by exerting its direct immune-modulating effects (Zhu et al., 2004), defining anti-inflammatory macrophages (Mausberg et al., 2011), inducing Treg cells, and possibly also inhibiting chemokines to reduce leukocyte recruitment in our EAN model (Wahl et al., 2004). Although the exact inducing mechanism remains unclear, our present data suggest that the clearance of apoptotic cells promoted by RvD1 may play an important role.

Finally, we found that RvD1 contributed to the induction of Treg cells in EAN. Accumulating evidence has revealed the contribution of Treg cells to promoting the resolution of the inflammatory response in autoimmune inflammatory disorders such as rheumatoid arthritis (Sarkar and Fox, 2008), multiple sclerosis and its animal model EAE (Korn et al., 2007; Aranami and Yamamura, 2008; Lu et al., 2008), and specifically in EAN (Zhang et al., 2009b; Wang et al., 2014). Our previous observations found an increase in Treg-cell numbers during the spontaneous recovery phase of EAN (Zhang et al., 2009b). Furthermore, we and others have shown that the induction of Treg cells by treatments contributed to the amelioration of EAN (Li et al., 2011; Xu et al., 2014). Moreover, the depletion of Treg cells exacerbated EAN progression, further confirming the important role of Treg cells in EAN (Meyer zu Hörste et al., 2014). Given the important contribution of Treg cells to EAN inflammation regulation, the pathways regulating Treg-cell induction in EAN remain unknown. The present data revealed that RvD1-induced TGF- $\beta$ promotes the macrophage phagocytosis of apoptotic $T$ cells, which contributes to the increase in Treg-cell numbers in EAN.

Collectively, our results reveal a novel pathway that promotes inflammation resolution and identify the essential position of
RvD1 in orchestrating the resolution of the autoimmune inflammation in EAN. Given its central role in disease recovery of EAN, its low toxicity, and its safety as an endogenous lipid mediator derived from the DHA, RvD1 shows potential utility for the treatment of EAN.

\section{References}

Annunziato F, Cosmi L, Liotta F, Maggi E, Romagnani S (2008) The phenotype of human Th17 cells and their precursors, the cytokines that mediate their differentiation and the role of Th17 cells in inflammation. Int Immunol 20:1361-1368. CrossRef Medline

Aranami T, Yamamura T (2008) Th17 Cells and autoimmune encephalomyelitis (EAE/MS). Allergol Int 57:115-120. CrossRef Medline

Ariel A, Fredman G, Sun YP, Kantarci A, Van Dyke TE, Luster AD, Serhan CN (2006) Apoptotic neutrophils and $\mathrm{T}$ cells sequester chemokines during immune response resolution through modulation of CCR5 expression. Nat Immunol 7:1209-1216. CrossRef Medline

Brunn A, Mihelcic M, Carstov M, Hummel L, Geier F, Schmidt A, Saupe L, Utermöhlen O, Deckert M (2014) IL-10, IL-4, and STAT6 promote an M2 milieu required for termination of $\mathrm{P} 0(106-125)$-induced murine experimental autoimmune neuritis. Am J Pathol 184:2627-2640. CrossRef Medline

Chang HY, Lee HN, Kim W, Surh YJ (2015) Docosahexaenoic acid induces M2 macrophage polarization through peroxisome proliferator-activated receptor gamma activation. Life Sci 120:39-47. CrossRef Medline

Czaja AJ (2014) Current and prospective pharmacotherapy for autoimmune hepatitis. Expert Opin Pharmacother 15:1715-1736. CrossRef Medline

Fadok VA, Bratton DL, Konowal A, Freed PW, Westcott JY, Henson PM (1998) Macrophages that have ingested apoptotic cells in vitro inhibit proinflammatory cytokine production through autocrine/paracrine mechanisms involving TGF-beta, PGE2, and PAF. J Clin Invest 101:890898. CrossRef Medline

Fang Y, Sharp GC, Braley-Mullen H (2011) Effect of transgenic overexpression of FLIP on lymphocytes on development and resolution of experimental autoimmune thyroiditis. Am J Pathol 179:1211-1220. CrossRef Medline

Fujita E, Shimizu A, Masuda Y, Kuwahara N, Arai T, Nagasaka S, Aki K, Mii A, Natori Y, Iino Y, Katayama Y, Fukuda Y (2010) Statin attenuates experimental anti-glomerular basement membrane glomerulonephritis together with the augmentation of alternatively activated macrophages. Am J Pathol 177:1143-1154. CrossRef Medline

Hong S, Gronert K, Devchand PR, Moussignac RL, Serhan CN (2003) Novel docosatrienes and 17S-resolvins generated from docosahexaenoic acid in murine brain, human blood, and glial cells. Autacoids in antiinflammation. J Biol Chem 278:14677-14687. CrossRef Medline

Hughes RA, Cornblath DR (2005) Guillain-Barre syndrome. Lancet 366 : 1653-1666. CrossRef Medline

Huynh ML, Fadok VA, Henson PM (2002) Phosphatidylserine-dependent ingestion of apoptotic cells promotes TGF-betal secretion and the resolution of inflammation. J Clin Invest 109:41-50. CrossRef Medline

Italiani P, Boraschi D (2014) From monocytes to M1/M2 macrophages: phenotypical vs. functional differentiation. Front Immunol 5:514. CrossRef Medline

Jha P, Matta B, Lyzogubov V, Tytarenko R, Bora PS, Bora NS (2007) Crucial role of apoptosis in the resolution of experimental autoimmune anterior uveitis. Invest Ophthalmol Vis Sci 48:5091-5100. CrossRef Medline

Korn T, Reddy J, Gao W, Bettelli E, Awasthi A, Petersen TR, Bäckström BT, Sobel RA, Wucherpfennig KW, Strom TB, Oukka M, Kuchroo VK (2007) Myelin-specific regulatory T cells accumulate in the CNS but fail to control autoimmune inflammation. Nat Med 13:423-431. CrossRef Medline

Krishnamoorthy S, Recchiuti A, Chiang N, Yacoubian S, Lee CH, Yang R, Petasis NA, Serhan CN (2010) Resolvin D1 binds human phagocytes with evidence for pro-resolving receptors. Proc Natl Acad Sci U S A 107: 1660-1665. CrossRef Medline

Levy BD (2010) Resolvins and protectins: natural pharmacophores for resolution biology. Prostaglandins Leukot Essent Fatty Acids 82:327-332. CrossRef Medline

Li XL, Dou YC, Liu Y, Shi CW, Cao LL, Zhang XQ, Zhu J, Duan RS (2011) Atorvastatin ameliorates experimental autoimmune neuritis by decreased 
Th1/Th17 cytokines and up-regulated T regulatory cells. Cell Immunol 271:455-461. CrossRef Medline

Lu L, Kim HJ, Werneck MB, Cantor H (2008) Regulation of CD8+ regulatory T cells: Interruption of the NKG2A-Qa-1 interaction allows robust suppressive activity and resolution of autoimmune disease. Proc Natl Acad Sci U S A 105:19420-19425. CrossRef Medline

Luchting B, Rachinger-Adam B, Heyn J, Hinske LC, Kreth S, Azad SC (2015) Anti-inflammatory T-cell shift in neuropathic pain. J Neuroinflammation 12:12. CrossRef Medline

Mausberg AK, Meyer Zu Hörste G, Dehmel T, Stettner M, Lehmann HC, Sheikh KA, Kieseier BC (2011) Erythropoietin ameliorates rat experimental autoimmune neuritis by inducing transforming growth factorbeta in macrophages. PLoS One 6:e26280. CrossRef Medline

Meyer zu Hörste G, Cordes S, Mausberg AK, Zozulya AL, Wessig C, Sparwasser T, Mathys C, Wiendl H, Hartung HP, Kieseier BC (2014) FoxP3+ regulatory $\mathrm{T}$ cells determine disease severity in rodent models of inflammatory neuropathies. PLoS One 9:e108756. CrossRef Medline

Orteu CH, Rustin MH, O’Toole E, Sabin C, Salmon M, Poulter LW, Akbar AN (2000) The inhibition of cutaneous $T$ cell apoptosis may prevent resolution of inflammation in atopic eczema. Clin Exp Immunol 122: 150-156. CrossRef Medline

Pay S, Musabak U, Simsek I, Erdem H, Pekel A, Sengul A, Dinc A (2007) Synovial lymphoid neogenetic factors in Behcet's synovitis: do they play a role in self-limiting and subacute course of arthritis? Clin Exp Rheumatol 25:S21-S26. Medline

Pilartz M, Jess T, Indefrei D, Schröder JM (2002) Adoptive transferexperimental allergic neuritis in newborn Lewis rats results in inflammatory infiltrates, mast cell activation, and increased Ia expression with only minor nerve fiber degeneration. Acta Neuropathol 104:513-524. Medline

Recchiuti A (2013) Resolvin D1 and its GPCRs in resolution circuits of inflammation. Prostaglandins Other Lipid Mediat 107:64-76. CrossRef Medline

Sarkar S, Fox DA (2008) Regulatory T cells in rheumatoid arthritis. Curr Rheumatol Rep 10:405-412. CrossRef Medline

Shen Y, Wei Y, Wang Z, Jing Y, He H, Yuan J, Li R, Zhao Q, Wei L, Yang T, Lu J (2015) TGF-beta regulates hepatocellular carcinoma progression by inducing Treg cell polarization. Cell Physiol Biochem 35:1623-1632. CrossRef Medline

Sindrilaru A, Scharffetter-Kochanek K (2013) Disclosure of the culprits: macrophages-versatile regulators of wound healing. Adv Wound Care (New Rochelle) 2:357-368. CrossRef Medline

Soliven B (2012) Autoimmune neuropathies: insights from animal models. J Peripher Nerv Syst 17:28-33. CrossRef Medline

Spite M, Summers L, Porter TF, Srivastava S, Bhatnagar A, Serhan CN (2009) Resolvin D1 controls inflammation initiated by glutathione-lipid conjugates formed during oxidative stress. Br J Pharmacol 158:1062-1073. CrossRef Medline

Sun YP, Oh SF, Uddin J, Yang R, Gotlinger K, Campbell E, Colgan SP, Petasis NA, Serhan CN (2007) Resolvin D1 and its aspirin-triggered 17R epimer: stereochemical assignments, anti-inflammatory properties, and enzymatic inactivation. J Biol Chem 282:9323-9334. CrossRef Medline

Tabas I, Glass CK (2013) Anti-inflammatory therapy in chronic disease: challenges and opportunities. Science 339:166-172. CrossRef Medline

Titos E, Rius B, González-Périz A, López-Vicario C, Morán-Salvador E,
Martínez-Clemente M, Arroyo V, Clària J (2011) Resolvin D1 and its precursor docosahexaenoic acid promote resolution of adipose tissue inflammation by eliciting macrophage polarization toward an M2-like phenotype. J Immunol 187:5408-5418. CrossRef Medline

Wahl SM, Swisher J, McCartney-Francis N, Chen W (2004) TGF-beta: the perpetrator of immune suppression by regulatory $\mathrm{T}$ cells and suicidal $\mathrm{T}$ cells. J Leukoc Biol 76:15-24. CrossRef Medline

Wang X, Haroon F, Karray S, Martina Deckert, Schlüter D (2013) Astrocytic Fas ligand expression is required to induce T-cell apoptosis and recovery from experimental autoimmune encephalomyelitis. Eur J Immunol 43: 115-124. CrossRef Medline

Wang X, Zheng XY, Ma C, Wang XK, Wu J, Adem A, Zhu J, Zhang HL (2014) Mitigated Tregs and augmented Th17 cells and cytokines are associated with severity of experimental autoimmune neuritis. Scand J Immunol 80:180-190. CrossRef Medline

Weishaupt A, Schönrock LM, Stienekemeier M, Toyka KV, Gold R (2001) Glucocorticosteroids modulate antigen-induced T cell apoptosis in experimental autoimmune neuritis and cause $\mathrm{T}$ cell proliferation in situ. Acta Neuropathol 102:75-82. Medline

Xu H, Li XL, Yue LT, Li H, Zhang M, Wang S, Wang CC, Duan RS (2014) Therapeutic potential of atorvastatin-modified dendritic cells in experimental autoimmune neuritis by decreased Th1/Th17 cytokines and upregulated T regulatory cells and NKR-P1(+) cells. J Neuroimmunol 269: 28-37. CrossRef Medline

Yun JH, Henson PM, Tuder RM (2008) Phagocytic clearance of apoptotic cells: role in lung disease. Expert Rev Respir Med 2:753-765. CrossRef Medline

Yun W, Hua-bing W, Wei-zhi W (2007) A study of associated cell-mediated immune mechanisms in experimental autoimmune neuritis rats. J Neuroimmunol 185:87-94. CrossRef Medline

Zettl UK, Gold R, Hartung HP, Toyka KV (1994) Apoptotic cell death of T-lymphocytes in experimental autoimmune neuritis of the Lewis rat. Neurosci Lett 176:75-79. CrossRef Medline

Zhang HL, Hassan MY, Zheng XY, Azimullah S, Quezada HC, Amir N, Elwasila M, Mix E, Adem A, Zhu J (2012) Attenuated EAN in TNF-alpha deficient mice is associated with an altered balance of M1/M2 macrophages. PLoS One 7:e38157. CrossRef Medline

Zhang ZY, Zhang Z, Schluesener HJ (2010) MS-275, an histone deacetylase inhibitor, reduces the inflammatory reaction in rat experimental autoimmune neuritis. Neuroscience 169:370-377. CrossRef Medline

Zhang ZY, Schluesener HJ, Zhang Z (2011) Distinct expression of Tim-3 during different stages of rat experimental autoimmune neuritis. Brain Res Bull 86:229-234. CrossRef Medline

Zhang Z, Zhang ZY, Schluesener HJ (2009a) Compound A, a plant origin ligand of glucocorticoid receptors, increases regulatory T cells and M2 macrophages to attenuate experimental autoimmune neuritis with reduced side effects. J Immunol 183:3081-3091. CrossRef Medline

Zhang Z, Zhang ZY, Fauser U, Schluesener HJ (2009b) Distribution of Foxp3(+) T-regulatory cells in experimental autoimmune neuritis rats. Exp Neurol 216:75-82. CrossRef Medline

Zhu W, Mix E, Nennesmo I, Adem A, Zhu J (2004) Anti-cytokine autoantibodies in experimental autoimmune neuritis in Lewis rats. Exp Neurol 190:486-494. CrossRef Medline 